\title{
Current Topics in Microbiology and Immunology
}

\section{Chapter 8}

\section{The regulation of IL-10 expression}

\author{
Leona Gabryšová, Ashleigh Howes, Margarida Saraiva and Anne O’Garra
}

\begin{abstract}
Interleukin (IL)-10 is an important immunoregulatory cytokine and an understanding of how IL-10 expression is controlled is critical in the design of immune intervention strategies. IL-10 is produced by almost all cell types within the innate (including macrophages, monocytes, dendritic cells (DCs), mast cells, neutrophils, eosinophils and natural killer cells) and adaptive (including $\mathrm{CD}^{+} \mathrm{T}$ cells, $\mathrm{CD}^{+} \mathrm{T}$ cells and $\mathrm{B}$ cells) immune systems. The mechanisms of IL-10 regulation operate at several stages including chromatin remodelling at the $I l 10$ locus, transcriptional regulation of $I l 10$ expression, and post-transcriptional regulation of $I l l O$ mRNA. In addition, whereas some aspects of $I l 10$ gene regulation are conserved between different immune cell types, several are cell type- or stimulus-specific. Here we outline the complexity of IL-10 production by discussing what is known about its regulation in macrophages, monocytes, DCs and $\mathrm{CD}^{+} \mathrm{T}$ helper cells.
\end{abstract}

\section{Contents}

8 Chapter 8

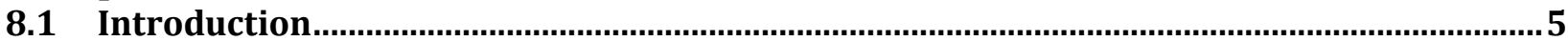

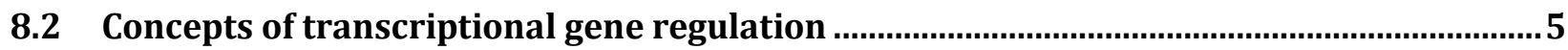

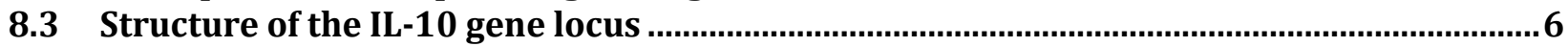

8.4 Molecular Signals and Transcriptional Regulation of IL-10 Expression................................ 7

8.4.1 The Regulation of IL-10 in Macrophages and Dendritic Cells ..........................................................8

8.4.1.1 The Regulation of IL-10 Downstream of Pattern Recognition Receptors.......................................... 8

8.4.1.2 Negative Regulators of IL-10 Production......................................................................................... 12

8.4.1.3 The Modulation of IL-10 Production by Autocrine and Paracrine Factors ..................................... 13

8.4.2 Transcriptional Regulation of IL-10 in CD4+ T Helper Cells ...........................................................14

8.4.2.1 The Regulation of IL-10 by T Cell Receptor Signalling ...................................................................... 15

8.4.2.2 The Regulation IL-10 by Cytokine Signalling................................................................................... 17

8.4.2.3 The Role of T Helper Cell Master Regulators in IL-10 Regulation .................................................. 18

8.4.2.4 The Role of Other Transcription factors in IL-10 Regulation........................................................ 18

8.4.2.5 The regulation of IL-10 by Notch Signalling ....................................................................................... 21

8.4.2.6 Negative Regulators of IL-10 Production.......................................................................................... 21

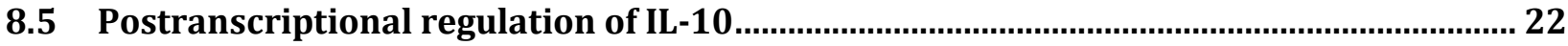

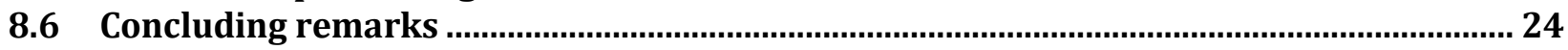

\section{Total 9,395 words}

Anne O’Garra (corresponding author, aogarra@nimr.mrc.ac.uk), Leona Gabryšová and Ashleigh Howes

Division of Immunoregulation

MRC National Institute for Medical Research

The Ridgeway

Mill Hill

London NW7 1AA

United Kingdom

Anne O'Garra is also Professor of Infection Immunology at ${ }^{2}$ Department of Respiratory Medicine, Imperial College Healthcare NHS Trust, St. Mary’s Hospital, London W2 1NY, UK 
Margarida Saraiva

Microbiology and Infection Research Domain

Life and Health Sciences Research Institute (ICVS)

School of Health Sciences, University of Minho

and

ICVS/3B's - PT Government Associate Laboratory, Braga/Guimarães, Portugal Campus Gualtar

4710-057 Braga, Portugal 


\section{List of Abbreviations:}

\begin{tabular}{|c|c|}
\hline AHR & Aryl hydrocarbon receptor \\
\hline AP-1 & Activator protein 1 \\
\hline $\mathrm{APC}$ & Antigen presenting cell \\
\hline ARE & AU rich element \\
\hline ATF & Activating transcription factor 1 \\
\hline AUF-1 & ARE/poly(U) binding degradation factor 1 \\
\hline BATF & basic leucine zipper transcription factor ATF-like transcription factor \\
\hline BCL-6 & B-cell lymphoma 6 \\
\hline BLIMP-1 & PR domain zinc finger protein 1 \\
\hline $\mathrm{BM}$ & Bone marrow \\
\hline $\mathrm{C} / \mathrm{EBP}$ & CCAAT/enhancer-binding protein \\
\hline cAMP & cyclic adenosine monophosphate \\
\hline CBP & CREB-binding protein \\
\hline CD40L & CD40 ligand \\
\hline ChIP-Seq & Chromatin immunoprecipitation-sequencing \\
\hline CNS & Conserved non-coding sequences \\
\hline CREB & cAMP response element-binding protein \\
\hline CRTC3 & CREB-regulated transcription coactivator 3 \\
\hline DC & Dendritic cell \\
\hline DLL & Delta-like Notch ligands \\
\hline DRE & Distal regulatory element \\
\hline DUSP1 & Dual-specificity phosphatase-1 \\
\hline E4BP4 & E4 promoter-binding protein 4 \\
\hline ERK & Extracellular signal-regulated kinase \\
\hline E. coli & Escherichia coli \\
\hline ETS-1 & E26 transformation-specific 1 \\
\hline GATA3 & GATA binding protein 3 \\
\hline GM-CSF & Granulocyte-monocyte colony stimulating factor \\
\hline GSK3 & Glycogen synthase kinase 3 \\
\hline HAT & Histone acetyl transferase \\
\hline HDAC & Histone deacetylase \\
\hline HMT & Histone methyl transferase \\
\hline HSS & DNaseI hypersensitive sites \\
\hline ICOS & Inducible $\mathrm{T}$ cell costimulator \\
\hline IFN & Interferon \\
\hline IL & Interleukin \\
\hline IRF & Interferon regulatory factors \\
\hline JDP & Jun dimerising protein \\
\hline LPS & Lipopolysaccharide \\
\hline MAP kinase & Mitogen-activated protein kinase \\
\hline MARE & c-MAF responsive element \\
\hline $\mathrm{mDC}$ & Myeloid dendritic cell \\
\hline MHC & Major histocompatibility complex \\
\hline miRNA & MicroRNA \\
\hline MSK1/2 & Mitogen- and stress-activated protein kinases $1 / 2$ \\
\hline mTOR & mammalian target of rapamycin \\
\hline M. tuberculosis & Mycobacterium tuberculosis \\
\hline MyD88 & Myeloid differentiation factor 88 \\
\hline $\mathrm{NF}-\kappa \mathrm{B}$ & Nuclear factor $-\kappa B$ \\
\hline NFAT & Nuclear factor of activated T cells \\
\hline PBX1 & Pre-B cell leukaemia homeobox 1 \\
\hline $\mathrm{pDC}$ & Plasmocytoid dendritic cell \\
\hline PDCD4 & Programmed cell death 4 \\
\hline PGE2 & Prostaglandin E2 \\
\hline $\mathrm{PI}(3) \mathrm{K}$ & Phosphatidylinositol 3 kinase \\
\hline PKA & Protein Kinase A \\
\hline PKR & Protein-kinase $\mathrm{R}$ \\
\hline PREP1 & PBX-regulating protein 1 \\
\hline PRR & Pattern recognition receptor \\
\hline $\mathrm{ROR} \gamma \mathrm{t}$ & RAR-related orphan receptor gamma $t$ \\
\hline SIK2 & Salt-inducible kinase 2 \\
\hline
\end{tabular}


Sp1/3

STAT

SWI/SNF

SYK

TBET

TCR

Tfh

TGF

Th

TLR

TNF

TPL-2

TRIF

TSS

TTP

UTR
Specific protein $1 / 3$

Signal transducer and activator of transcription

Switching-defective-sucrose non-fermenting

Spleen tyrosine kinase

T-box transcription factor

$\mathrm{T}$ cell receptor

$\mathrm{T}$ follicular helper cell

Transforming growth factor

T helper cell

Toll-like receptor

Tumour necrosis factor

Tumour progression locus 2

TIR-domain-containing adapter-inducing interferon- $\beta$

Transcription start site

Tristetraprolin

Untranslated region 


\subsection{Introduction}

The immune system has evolved to protect the host from a wide range of potentially pathogenic microorganisms. However, immune responses also have the potential to cause damage to the host if not adequately regulated. Interleukin-10 (IL-10) is an anti-inflammatory cytokine with a crucial role in preventing inflammatory and autoimmune pathologies by limiting the immune response to pathogens and microbial flora. However, the production of IL-10 can also inappropriately restrict protective immune responses and, in this context, IL-10 can contribute to chronic infection [1]. Thus, IL-10 is an important immunoregulatory cytokine and an understanding of how IL-10 expression is regulated is critical in the design of immune intervention strategies.

IL-10 is produced by cells within both the innate (including macrophages, monocytes, dendritic cells (DCs), mast cells, neutrophils, eosinophils and natural killer cells) and adaptive (including $\mathrm{CD}^{+} \mathrm{T}$ cells, $\mathrm{CD}^{+} \mathrm{T}$ cells and $\mathrm{B}$ cells) immune systems [2]. Cells within the innate immune system require stimulation by pathogen derived products via pattern recognition receptors (PRR) to induce IL-10 production [2]. T cells recognise microbial peptides presented in the context of major histocompatibility complexes (MHC) by antigen presenting cells (APC) including macrophages and DCs through the interaction with their T cell receptor (TCR). In contrast to the innate cells that can immediately produce IL-10 in response to environmental stimuli, naïve CD4 ${ }^{+} \mathrm{T}$ cells first need to differentiate into the different $\mathrm{T}$ helper (Th) cell subsets, including Th1, Th2 and Th17 cells [3], in order to produce IL-10 [2].

The mechanisms of IL-10 regulation operate at several stages including chromatin remodelling at the $I l 10$ locus, transcriptional regulation of $I l 10$ expression, and post-transcriptional regulation of IllO mRNA. In addition, whereas some aspects of $I l 10$ gene regulation are conserved between different immune cell types, several may be cell type- or stimulus-specific. Here we outline the complexity of IL-10 regulation by discussing what is known about its regulation in macrophages, monocytes, DCs and CD4 ${ }^{+}$Th cells.

\subsection{Concepts of transcriptional gene regulation}

Within chromosomes, DNA is wrapped around octamers of core histones to form nucleosomes, the basic units of eukaryotic chromatin. Multiple nucleosomes are arranged in a linear array along the DNA referred to as 'beads on a string' (accessible euchromatin) that can be further compacted into 
$30 \mathrm{~nm}$ fibres (inaccessible heterochromatin) upon the addition of linker histones [4] (Figure 1). Factors that influence the accessibility of chromatin include DNA methylation, nucleosome remodelling and covalent histone modifications such as acetylation or methylation [5] (Figure 1). Histone modifications, usually referred to as the histone code, have been reported to be associated with different functional elements such as promoters or distal regulatory elements (DRE), also known as enhancers or insulators, and are key to gene regulation [6] (Figure 1). Histone modifying enzymes such as histone acetyl transferases (HAT) and deacetylases (HDAC) or histone methyl transferases (HMT) alter histone 'tails' to form repressive or active marks, remodelling the chromatin from high density transcriptionally inactive heterochromatin to low density transcriptionally active euchromatin and vice versa thus governing gene expression [5]. Changes in the chromatin landscape can be monitored by DNaseI treatment that marks nucleosome-poor regions, indicative of 'open' chromatin, known as hypersensitive sites (HSS), where transcription factors can interact with the exposed regulatory DNA sequences (Figure 1).

\subsection{Structure of the IL-10 gene locus}

The genes encoding both human and murine IL-10 are located within the $I l 10$ gene family cluster on Chromosome 1 of the respective genomes [7]. The $I l 10$ gene is flanked upstream by other members of the IL-10 family of cytokines $I l 19$, $I l 20$ and $I l 24$, and downstream by the Mapkapk2 (MAP kinase-activated protein kinase 2) gene (Figure 2a). The $I l 10$ gene itself is comprised of 5 exons and 4 introns followed by a 3' untranslated region (UTR) spanning around $5 \mathrm{~kb}$ in total on the forward strand (Figure $2 \mathrm{~b}$ and c). The $I l 10$ transcription start site (TSS) is relatively well defined, with proximal downstream TATA and $\mathrm{CCA}[\mathrm{A} / \mathrm{G}$ in mice]T elements within the core promoter (Figure 2d) characteristic of a 'sharp' or 'focused' promoter that is thought to be associated with tissue-specific transcription often in an environmentally responsive manner [6]. There is a high degree of homology between the human and mouse $I l 10$ gene loci with a number of conserved non-coding sequences (CNS, named according to their distance in kb from the IllO TSS) and shown to be present using VISTA-Point software [8] (Figure 2b and c). This is indicative of an evolutionary constraint most likely resulting from functional relevance of these regions, some of which have been shown to be functionally characterized as enhancers of $1 l 10$ gene expression [913].

Changes in chromatin structure at the $I l 10$ gene locus are fundamental to the regulation of its expression. Several studies in a variety of cells including both macrophages and Th cells have 
investigated the pattern of DNaseI HSSs at the $I l 10$ gene locus. In bone marrow (BM)-derived macrophages, four HSS sites have been identified at positions $-4.5,-2,-0.12 \mathrm{~kb}$ upstream and +1.65 and $+2.98 \mathrm{~kb}$ downstream of the Il10 TSS following their stimulation with pattern recognition receptors (PRR) ligands including lipopolysaccharide (LPS), CpG and zymosan A [14] (Figure 2c). The HSS -4.5 kb was also present in BM derived DCs when stimulated with the same ligands [14]. Unstimulated macrophages also showed some degree of sensitivity to DNaseI digestion at these sites suggestive of poised chromatin conformation in the resting state. This may be in line with the immediate expression of the $I l 10$ gene in these cells upon exposure to appropriate stimuli. In contrast, the $I l 10$ gene locus in naïve T cells is in a closed, transcriptionally inactive conformation with only one HSS $-8.8 \mathrm{~kb}$ upstream of the IllO TSS [12] (Figure 2b). Substantial remodelling of the $I l 10$ gene locus occurs upon differentiation into Th1 and Th2 cells, as demonstrated by the increased number of HSS sites detected, most of which were found to be present in both Th1 and Th2 cells [12-15] (Figure 2b and c, black arrows). A few HSS sites were more prominent in Th2 cells including HSS $-30.4,-29.8,-21,-17.5$ and $-0.12 \mathrm{~kb}$ downstream and $+6.45 \mathrm{~kb}$ upstream of the Il10 gene TSS [12] (Figure 2b and c, green arrows). These differences may account for the enhanced production of IL-10 in Th2 cells when compared to in Th1 cells, although this is yet to be investigated. In contrast to Th1 and Th2 cells, little is known about the chromatin conformation at the IllO gene locus in Th17 cells. Interestingly, many of the HSS studied were common between macrophages, DCs and Th cells, apart from HSS $-4.5 \mathrm{~kb}$ which was macrophage and DC specific [14]. Moreover, in most instances, the DNaseI HSS detected correspond with the computationally obtained CNS sites (Figure $2 \mathrm{~b}$ and c), further supporting a regulatory role for these CNS.

Additional evidence informing on the accessibility of the $I l 10$ gene locus comes from studies on histone modifications as markers of permissive versus repressive chromatin. In IL-10-producing macrophages, the presence of hyperactylation of histone $\mathrm{H} 4$ (active mark) was detected at the -4.5 and -1.2 kb HSS regions [14]. In Th1 and Th2 cells, the presence of H3K4me3 (active mark) and absence of H3K27me3 (repressive mark) was shown across the $I l 10$ gene locus by chromatin immunoprecipitation-sequencing (ChIP-Seq) [16]. These histone marks indicate a transcriptionally competent state of the $I l 10$ gene locus, although their presence does not always correlate with active gene expression. The possible candidates initiating chromatin remodelling at the $I l 10$ gene locus will be discussed in some detail later.

\subsection{Molecular Signals and Transcriptional Regulation of IL-10 Expression}




\subsubsection{The Regulation of IL-10 in Macrophages and Dendritic Cells}

Almost all cells within the innate immune system, with the exception of plasmacytoid DCs (pDC) [17-19], have been shown to produce IL-10. These include macrophages, monocytes and myeloid (or conventional) DCs (mDC), which largely require stimulation via PRRs to induce IL-10 production [2]. Additionally, co-stimulation of DCs with a PRR ligand and CD40 ligand (CD40L) or immune-complexes can enhance the production of IL-10 [20, 21]. Importantly, other signals, such as those received from autocrine or paracrine cytokines, can also modulate IL-10 production [22-25]. Thus, the ultimate level of IL-10 produced by macrophages or mDCs is determined by the integration of several molecular signals (Figure 3a).

\subsubsection{The Regulation of IL-10 Downstream of Pattern Recognition Receptors}

Amongst the PRRs, the Toll-like receptor (TLR) family is the best studied. TLRs can be expressed at the plasma membrane or endosomally and recognise a range of ligands including bacterial lipopeptides (TLR 2), viral RNAs (TLRs 3 and 7), LPS found in the cell wall of Gram-negative bacteria (TLR 4), flagellin (TLR 5), and CpG DNA (TLR 9) [26]. It has been shown that TLR expression may vary amongst macrophage, monocyte and DC subsets [27, 28]. For example in humans, TLR 7 and TLR 9 are more highly expressed on pDCs than monocytes or other DC subsets [27, 28]. In contrast, human monocytes have been shown to more highly express TLR 2 and TLR 4 [27]. Of note, these differences may not be conserved in the murine system where it has been shown that the majority of TLR mRNAs (with the exception of TLRs 3, 5 and 7) are similarly expressed in DC subsets [29]. The ligation of several TLRs including 2, 4, 5, 7 and 9 has been shown to induce the production of IL-10 in human and murine macrophages and mDCs [17, 18, 30-32], although, macrophages and mDCs may not have the same capacity to produce IL-10. For example, TLR 3 activation has been shown to induce IL-10 production in macrophages but not mDC [17], and TLR 9 ligation induces IL-10 production more readily in murine macrophages than $\mathrm{mDC}$, and not at all in pDC, despite all of these cell types expressing TLR 9 [17, 18]. Importantly however, in mDCs, the co-ligation of TLR 2 and Dectin-1, a C-type Lectin receptor which recognises fungal $\beta$-glucans [33], has been shown to enhance the level of IL-10 production relative to TLR2 or Dectin-1 stimulation alone [34]. This demonstrates that PRRs are able to cooperate in their induction of IL10, a concept which may have relevance in the context of infection when several PRR ligands are likely to be present at the same time. 
Downstream of TLR ligation, adaptor proteins are essential for signal transduction. The adaptor myeloid differentiation factor 88 (MyD88) is required for signalling downstream of all TLRs with the exception of TLR 3 which utilises the adaptor TIR-domain-containing adapter-inducing interferon- $\beta$ (TRIF). TLR 4 is the only TLR that mediates signal transduction through both MyD88 and TRIF [26] and indeed both adaptors are required for optimal IL-10 production downstream of this receptor [17]. TLR signalling through these adaptor proteins leads to the activation of several signalling pathways including mitogen-activated protein kinase (MAP kinase) pathways, the phosphatidylinositol 3 kinase (PI(3)K)-AKT pathway, the nuclear factor (NF)- $\kappa B$ pathway and the activation of interferon regulatory factors (IRF). These downstream pathways collectively regulate the production of TLR-induced cytokines, including IL-10 [26] (Figure 3a).

Several studies have shown that the activation of the MAP kinases extracellular signal-regulated kinase (ERK) 1 and ERK 2 (here referred to collectively as ERK) is critical for the production of IL-10 in macrophages and mDCs downstream of TLRs 2, 4 and 9 [18, 35-37], and in Mycobacterium tuberculosis (M. tuberculosis) infected macrophages and monocytes [38]. In keeping with this, tumour progression locus 2 (TPL-2), the MAP 3-kinase upstream of TLRinduced ERK activation [39], which is itself regulated by the NF- $\kappa \mathrm{B}$ family member p105 [40], is also required for IL-10 production in TLR stimulated macrophages and $\mathrm{mDCs}$, and in $M$. tuberculosis infected macrophages and monocytes [18, 35, 38] (Figure 3a and b). In these cell types, the TPL-2/ERK pathway also negatively regulates type I IFN [18, 38] which as discussed in more detail later, is a positive regulator of IL-10 production [22, 38, 41-43] (Figure 3b). However, despite the relatively higher level of type I IFN produced in $T p l 2^{-/}$macrophages, $\mathrm{mDCs}$ and monocytes, IL-10 production remains reduced compared to wild type cells $[18,38]$. Together, this demonstrates a central role for the TPL-2/ERK pathway in the regulation of IL-10 that cannot be compensated for by elevated autocrine type I IFN production. Further supporting an important role for ERK in the regulation of IL-10, differential ERK activation has been correlated with the different levels of IL-10 produced by macrophages, mDCs and pDCs [18] and ERK activation promotes IL-10 production in mDC downstream of the non-TLR PRR Dectin-1 [44, 45].

Downstream of MAP kinase signalling transcription factors including activator protein 1 (AP-1), a heterodimeric transcription factor composed of dimers of the Fos, Jun, Jun dimerising protein (JDP) and activating transcription factor (ATF) family members are activated [46]. In TLR stimulated macrophages and mDCs, the AP-1 member c-FOS has been associated with the ERK-dependent positive regulation of IL-10 [18, 23, 30, 36]. In contrast to TLR-induced IL-10 production however, Dectin-1-dependent IL-10 induction requires the upstream kinase spleen tyrosine kinase (SYK) and 
is not dependent on c-FOS [44, 45, 47] (Figure 3a). In addition to the activation of AP-1, in macrophages co-stimulated with a TLR 4 ligand and immune-complexes, ERK activation has been shown to promote the phosphorylation of histone H3 at sites across the $I l 10$ promoter [48, 49]. This histone modification enhanced the accessibility of the $I l 10$ promoter, providing a permissive chromatin structure for the binding of transcription factors such as the constitutively expressed specific protein 1 (Sp1) [48, 49], shown to bind within the proximal IllO promoter at a site critical for transactivation of the $\mathrm{IllO}$ gene [50] (Figure 2d). Of note, in addition to Sp1, Sp3 has been reported to bind at the $I l 10$ promoter and transactivate the $I l 10$ gene in the Drosophila SL2 cell line [51]. The concept of chromatin remodelling at the $I l 10$ locus prior to $I l 10$ gene expression is in keeping with the dependence of $I l 10$ gene expression on the activity of SWI/SNF (switchingdefective-sucrose non-fermenting, also known as BRG1 associated factors in mammals) nucleosome remodelling complex which enhances accessibility of certain genetic loci in response to TLR stimulation [52].

Similarly to ERK, the MAP kinase p38 has been shown to positively regulate IL-10 production in TLR stimulated macrophages, monocytes and mDCs [23, 32, 37, 53-55] (Figure 3a). In a TLR 4 stimulated human monocytic cell line, p38 was proposed to induce Sp1 binding to an alternative upstream Sp1 binding site which was important for the transactivation of the $I l 10$ gene in this system [56]. Also downstream of p38, pre-B cell leukaemia homeobox 1 (PBX1) and PBXregulating protein 1 (PREP1) have been shown to promote IL-10 production in response to apoptotic cells [57].

ERK and p38 may also cooperate in their regulation of IL-10 production, demonstrated by the finding that both ERK and p38 contribute to the activation of mitogen- and stress-activated protein kinases MSK1 and MSK2 which in turn promote IL-10 production in TLR 4 stimulated macrophages [58]. Downstream of MSK1 and MSK2, the transcription factors cyclic adenosine monophosphate (CAMP) response element-binding protein (CREB) and ATF1 were found to bind the $I l 10$ promoter (Figure 2d) [58]. CREB and ATF1 binding at the $I l 10$ gene locus and transactivation of the $I l 10$ promoter has also been demonstrated in a cAMP treated human monocytic cell line [59]. CREB has further been shown to induce IL-10 production in response to Zymosan, a yeast derived combined TLR 2/Dectin-1 stimulus [60].

The third MAP kinase, JNK, has also been proposed to positively regulate IL-10 production in TLR stimulated macrophages and monocytes [23, 32, 61]. However, the downstream mechanisms of this 
are unclear and detailed studies of the role of JNK in the regulation of IL-10 have until recently been complicated by the lack of specific inhibitors for this kinase.

TLR-induced signalling through the PI(3)K-AKT pathway also contributes to IL-10 production in macrophages, monocytes and mDCs [62-64] (Figure 3a). In TLR 4 stimulated mDCs and Leishmania infected macrophages, this has been shown to be mediated at least in part through the inhibition of glycogen synthase kinase 3 (GSK3)- $\beta$ [63, 65], a constitutively active kinase which inhibits the production of IL-10 by antagonising the DNA binding activity of CREB [66]. It has also been proposed that the PI(3)K-AKT pathway activates ERK [62] and this may promote IL-10. The PI(3)K-AKT pathway additionally leads to the downstream activation of mammalian target of rapamycin (mTOR) and this also promotes the production of IL-10 [63, 64] (Figure 3a). Recently it has been shown that the MAP kinase p38 can also activate mTOR, providing an additional mechanism whereby p38 activation promotes the production of IL-10 production [67]. mTOR may further regulate IL-10 production through the activation of signal transducers and activators of transcription (STAT) 3 [64], reported to bind at a STAT consensus site within the proximal IllO promoter, important for transactivation of the $I l 10$ gene [68] (Figure 2d). Of note however, STAT3 activation also occurs downstream of the IL-10 receptor [69] and in human monocyte-derived macrophages STAT3 has been implicated in the feed-forward loop whereby IL-10 positively regulates its own production [24]. Thus, whether STAT3 regulates IL-10 downstream of PRR stimulation via mTOR, or downstream of autocrine IL-10 signalling, or both, is unclear.

$\mathrm{NF}-\kappa \mathrm{B}$ is also activated in response to TLR ligation (Figure 3a) and the finding that IKK2 deficient macrophages, which have impaired NF- $\mathrm{BB}$ activation, show reduced production of IL-10 [70] implicated NF- $\kappa B$ in the regulation of IL-10. Although the interpretation of this result is difficult as IKK2 is also upstream of TPL-2 activation [40], later studies have continued to support a role for $\mathrm{NF}-\kappa \mathrm{B}$ in the regulation of IL-10. For example, an NF- $\kappa \mathrm{B}$ binding site is present at HSS $-4.5 \mathrm{~kb}$ upstream of the IllO TSS and recruits the NF- $\mathrm{BB}$ subunit p65 in TLR 4 stimulated macrophages [14] (Figure 2c). Further, p105 (encoded by $N f k b l$ ) has been shown to regulate IL-10 production

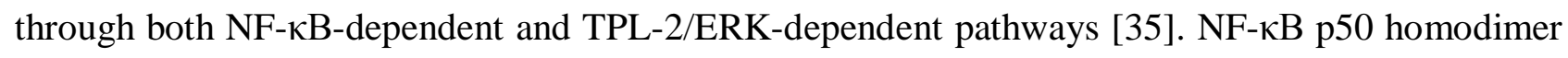
recruitment to an NF- $\kappa \mathrm{B}$ site proximal to the Ill0 TSS has also been shown to promote IL-10 production in TLR 4 stimulated macrophages (Figure 2d) and the complexing of these p50 homodimers with the co-activator CREB-binding protein (CBP) further enhances $I l 10$ promoter activity [71]. Finally, p65 binding at an additional site in the $I l 10$ promoter (Figure $2 \mathrm{~d}$ ) has been reported to upregulate IL-10 in dsRNA-stimulated macrophages and this was dependent on proteinkinase R (PKR) [61]. 
Several other transcription factors have been implicated in the regulation of $I l 10$ gene expression in PRR stimulated macrophages and/or mDCs. The transcription factor c-MAF has been reported to bind at the $I l 10$ promoter (Figure 2d) and enhance IL-10 production in LPS stimulated macrophages, although this mechanism of IL-10 regulation may be most relevant in the context of IL-4 which increases the recruitment of c-MAF to the Illo promoter [25]. Several CCAAT/enhancer-binding protein (C/EBP) sites have been identified within the 1110 promoter [72]. In a human monocyte cell line, binding of $\mathrm{C} / \mathrm{EBP} \alpha$ and $\beta$ to a $\mathrm{C} / \mathrm{EBP}$ site proximal to the TATA box was important for basal $I l 10$ gene expression and transactivation of the $I l 10$ gene in response to cAMP [72]. Roles for $\mathrm{C} / \mathrm{EBP} \beta$ and $\mathrm{C} / \mathrm{EBP} \delta$ in cooperation with $\mathrm{Sp} 1$, have also been identified in the expression of $I l 10$ in a TLR 4 stimulated murine macrophage cell line [73]. C/EBP $\beta$ has further been shown to mediate $I l 10$ expression downstream of the $\mathrm{A}_{2 \mathrm{~A}}$ adenosine receptor in Escherichia $\operatorname{coli}$ (E. coli) infected macrophages [74]. Of note, the synergistic induction of IL-10 in adenosine/E. coli infected macrophages was dependent on p38 activation [74] suggesting that p38 may be upstream of C/EBP $\beta$ activity. The ligand-activated transcription factor aryl hydrocarbon receptor (AHR) is additionally reported to be required for maximal production of IL-10 in TLR 4 but not TLR 9 stimulated macrophages, suggesting a stimulus specific requirement for AHR in the regulation of IL-10 [75].

\subsubsection{Negative Regulators of IL-10 Production}

Negative mechanisms of IL-10 regulation in PRR stimulated macrophages and monocytes have also been identified, in keeping with the important biological functions of IL-10 in various scenarios, and the need for tight control of its expression. For example, in a TLR 4 stimulated macrophage cell line, the chromatin modifying activity of HDAC11 has been shown to inhibit IL-10 production, possibly by impairing the transition of repressed to active chromatin at the 1110 locus and restricting the binding of Sp1, STAT3 and PolII to the proximal 1110 promoter [76]. Recently, IRF5, the expression of which is induced downstream of TLR ligation, has been identified as a negative regulator of IL-10 in human GM-CSF differentiated monocytes [77]. This study also showed recruitment of IRF5 to the IL-10 promoter, suggesting a direct mechanism of transcriptional inhibition [77]. IL-10 is additionally negatively regulated at the post-transcriptional level, discussed in detail later. 
Signalling induced by environmental cytokines can modulate the level of IL-10 produced by PRR stimulated macrophages or mDCs (Figure 3a). A key example of this is the effect of IL-10 on itself. In addition to the already mentioned activation of STAT3 which can enhance IL-10 production [24], IL-10 signalling has been shown to upregulate the expression of Tpl2 [78] (Figure 3b) which also positively regulates IL-10 [18, 35, 38]. In contrast, IL-10 can induce the expression of dualspecificity phosphatase-1 (DUSP1) which negatively regulates $\mathrm{p} 38$ activation, a positive regulator of IL-10 production [79].

Type I interferon (IFN) has been shown to enhance the production of IL-10 from TLR 4 stimulated murine macrophages and human monocytes [22, 41, 42]. Type I IFN also promotes IL-10 production in $M$. tuberculosis infected macrophages $[38,43]$. Reported mechanisms of type I IFN enhancement of IL-10 production in PRR stimulated cells include the recruitment of IRF1 and STAT3 to the $I l 10$ promoter in a human B cell line [80], the activation of STAT1 in murine macrophages [81] and the activation of the PI(3)K-AKT pathway followed by the subsequent inactivation of GSK3- $\beta$ in human DCs [82]. It has also been reported that IL-27 is required for the maximal induction of IL-10 by type I IFN in TLR 4 stimulated murine macrophages [83], however another study reported that resting murine macrophages are unresponsive to IL-27 and that IL-27 had an inhibitory effect on IL-10 production in human monocytes via STAT1 [84]. Thus, the role of IL-27 and STAT1 in the regulation of IL-10 remains incompletely understood. In contrast to type I IFN, in TLR 2 activated human macrophages, IFN- $\gamma$ has been shown to reduce the production of IL-10 through the inhibition of MAP kinases and enhancement of GSK3- $\beta$ activity [23]. This led to the suppression of the transcription factors AP-1 and CREB, which both positively regulate IL-10 [23].

The enhancement of IL-10 by the lipid-derived molecule prostaglandin E2 (PGE2) in TLR 4 activated macrophages has also been reported [85], illustrating that factors other than cytokines can modulate the production of PRR induced IL-10 production. A model for the mechanism of PGE2 mediated enhancement of IL-10 has been proposed in which PGE2 treatment activates protein kinase A (PKA) to phosphorylate salt-inducible kinase 2 (SIK2) [86, 87]. This inhibits the ability of SIK2 to phosphorylate CREB-regulated transcription coactivator 3 (CRTC3), permitting CRTC3 to translocate to the nucleus and act as a coactivator of CREB, ultimately enhancing IL-10 production [86, 87]. 
Thus, PRR activation induces IL-10 production in macrophages and mDCs with further modulation of IL-10 levels by other environmental cues. However, there are still many incompletely understood aspects of IL-10 regulation in macrophages, monocytes and DCs. For example, how signalling pathways from multiple PRRs, or PRRs in combination with signals from environmental factors such as cytokines are integrated to either positively or negatively regulate $I l 10$ expression is not clear. Further, it is not fully understood if the ability of certain PRRs (e.g. TLR 3 and TLR 9) to more efficiently induce the production of IL-10 in macrophages compared DCs [17, 18] is a consequence of cell type-specific signal transduction pathways, or if it is also contributed to by a differing chromatin state of the $I l 10$ locus in the distinct immune cell types. In addition, most molecular studies investigating the regulation of $I l 10$ have been conducted in TLR 4 stimulated cells. Thus, the continuation of studies delineating the common and distinct factors required for $I l 10$ expression downstream of other TLR and non-TLR PRRs will enhance our understanding of IL-10 regulation in various immune scenarios.

\subsubsection{Transcriptional Regulation of IL-10 in $\mathrm{CD4}^{+} \mathrm{T}$ Helper Cells}

Within the adaptive immune system, regulation of the $I l 10$ gene expression has been most extensively characterised in $\mathrm{CD}^{+}$Th cells. In contrast to macrophages and DCs that can instantly produce IL-10 in response to microbial products, naïve $\mathrm{CD} 4^{+} \mathrm{T}$ cells first need to differentiate into the different effector Th cell subsets in order to produce IL-10 [2]. The different Th cells subsets include Th1, Th2 and Th17 cells, each of which expresses a unique combination of cytokines that promote their specific effector functions [3]. The distinct Th cell fates are determined by the STAT family of transcription factors signalling downstream of cytokines present in the environment during $\mathrm{T}$ cell activation and are ultimately controlled by the subsequent induction of lineage specific master regulators. Th1 differentiation is driven predominantly by IL-12 signalling through STAT4 [88] the expression of the master regulator T-box transcription factor (TBET) that induces the production of the Th1 hallmark cytokine IFN- $\gamma$ [89]. Th2 differentiation requires IL-4 signalling through STAT6 and the expression of the master regulator GATA binding protein 3 (GATA3) [90] that induces the production of Th2 hallmark cytokines IL-4, IL-5 and IL-13 [91]. Th17 differentiation is dependent on transforming growth factor (TGF)- $\beta$ and IL-6, the latter of which signals through STAT3, and the expression of the master regulator RAR-related orphan receptor gamma $\mathrm{t}(\mathrm{ROR} \gamma \mathrm{t})$ that induces the production of the Th17 hallmark cytokine IL-17 [92, 93]. Interestingly, despite the differences in their developmental requirements outlined above, IL-10 has been shown to be produced by all of the different Th cell subsets [2]. In fact, the production of IL- 
10 by Th cells is tightly interlinked with each of their differentiation programmes. For example, strong TCR signalling, together with IL-12 and STAT4 are required for IL-10 production in Th1 cells [94], while IL-4 activation of STAT6 signalling and GATA3 are essential for IL-10 production in Th2 cells [16, 94-97], and TFG- $\beta$, IL-6 and STAT3 have been shown to drive the production of IL-10 in Th17 cells $[98,99]$. Additionally, type I IFN has been shown to promote IL-10 production by human $\mathrm{CD}^{+} \mathrm{T}$ cells $[41,100,101]$, although the downstream mediators of type I IFN and its effects on the different Th cell subsets are not defined (Figure 3c). Thus, the discrete signals required for IL-10 induction are tightly linked with those involved in directing the differentiation of each unique Th cell subset.

The current model of how Th cell identity is established involves a layered architecture of transcription factors induced downstream of the TCR and cytokine signalling pathways. The TCR signals are thought to induce pioneer factors able to bind closed chromatin that are, together with specific STATs, involved in the establishment of permissive epigenetic patterns across a broad range of Th cell genes in differentiating $\mathrm{CD}^{+} \mathrm{T}$ cells [102]. In contrast, targets of the master regulator transcription factors are thought to be more limited to a set of key genes crucial for lineage specificity, be it those involved in lineage reinforcement or in the limitation of alternative fate [102]. Since the production of IL-10 is so closely intertwined with $\mathrm{T}$ helper lineage specification, it is likely that this model would also apply to the regulation of IL-10, whereby layers of transcription factors, induced downstream of TCR and cytokine signalling or other environmental cues, act together to promote $I l 10$ gene expression (Figure 3c). However, the specific signalling cascades and transcription factor complexes that determine IL-10 production by the different Th cell subsets are still unclear.

\subsubsection{The Regulation of IL-10 by T Cell Receptor Signalling}

Following TCR activation, numerous signalling pathways are initiated leading to the induction, nuclear translocation and/or activation of downstream transcription factors including AP-1, nuclear factor of activated T cells (NFAT) and NF- $\kappa B$ [103] (Figure 3c).

Similarly to macrophages and DCs, the activation of the MAP kinase ERK has been shown to be a common positive regulator of IL-10 in the different Th cell subsets [94]. Of note, in contrast to TPL-2 driven ERK activation downstream of TLRs in macrophages and DCs [39], in T cells ERK is activated via Ras downstream of the TCR [104]. As already mentioned, the most prominent 
family of transcription factors induced downstream of ERK is AP-1. Binding of AP-1, comprised of JunB and to a lesser extent c-Jun [13], at the HSS $+6.45 \mathrm{~kb}$ in the $I l 10$ gene locus in Th2, but not Th1 cells has been demonstrated to enhance IL-10 expression using luciferase reporter assays [12, 13] (Figure 2c). Furthermore, retroviral expression of c-Jun and JunB in activated naïve $\mathrm{CD}^{+} \mathrm{T}^{-}$ cells showed a five-fold increase in IL-10 and to a lesser extent IFN- $\gamma$ production, while expression of a dominant negative c-Jun protein decreased the amount of IL-10 produced, thus confirming the role of Jun family proteins in IL-10 regulation [13]. More recently, the basic leucine zipper ATFlike transcription factor (BATF), another AP-1 family member, and the transcription factor IRF4 have been shown to cooperatively bind at CNS-9, in Th2, Th9 and Th17 cells as well as CD4 ${ }^{+} \mathrm{T}$ cells stimulated in the presence of IL-21 [9]. BATF has further been demonstrated to positively regulate IL-10 expression in Th2 cells, although its effect is only revealed in the absence of BATF3 [105]. Of note, the production of IL-4 in the Th2 driven Batf ${ }^{/-}$Batf $^{-/-} \mathrm{CD}^{+} \mathrm{T}$ cells was also significantly affected, indicative of a more general defect in the Th2 differentiation pathway as opposed to just IL-10 production [106]. In keeping, Irf $4^{-/-} \mathrm{CD} 4^{+} \mathrm{T}$ cells stimulated in the presence of IL-21 failed to express IL-10 mRNA when compared to the wild type T cells, although the effect on other cytokines was not assessed [9]. Mutating either the IRF or AP-1 motif within CNS-9 resulted in a diminished luciferase reporter activity in IL-21 stimulated CD4 ${ }^{+} \mathrm{T}$ cells consistent with functional cooperation between these factors in $I l 10$ gene regulation [9] (Figure 2c). Furthermore in Th2 cells, IRF4 alone has been shown to positively regulate IL-10 by binding to the Illo promoter and at CNS+6.45 [11] (Figure 2c). Of note, similarly to the effect of BATF on Th2 differentiation, IRF4 also increased the production of IL-4 in these cells by binding and transactivating the Il4 promoter, showing that IL-4 and IL-10 can be co-regulated in Th2 cells, suggesting a more general effect on Th2 cell differentiation, accompanied by IL-10 production [11].

Upon TCR activation, NFAT1 translocates from the cytoplasm into the nucleus where it is known to interact with AP-1 and other transcriptional partners to promote cytokine gene transcription [107]. NFAT1 has been shown to bind regions in the $I l 10$ promoter in Th2 and in intron 4 of the IllO gene locus in Th1 cell lines [15]. In a later study, NFAT1 binding further upstream at CNS-9 together with IRF4 has been shown to synergistically enhance IL-10 expression in Th2 cells using luciferase reporter assays [10] (Figure 2c). Furthermore, blocking of NFAT signalling with a cyclosporine A inhibitor also decreased IL-10 mRNA expression in differentiated Th2 as well as Th1 cells, although it is not known what effect it had on the hallmark cytokine production and therefore could represent a generalised effect on Th cell differentiation [10]. 
NF- $\kappa \mathrm{B}$ activation downstream of the TCR has been reported to play a role in the production of Th1 [108], Th2 [109] and Th17 hallmark cytokines [110]. Although NF-кB h

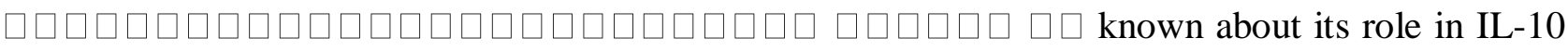
regulation in Th cells other than the reported binding of NF- $\kappa \mathrm{B} \square$ complexes at the $\square I l 10$ gene locus in a human T lymphoma line [111].

Thus, even though $\mathrm{CD}^{+} \mathrm{T}$ cell activation through the TCR is crucial for Th cell differentiation, the roles of factors downstream of the TCR in the regulation of IL-10 are only partially characterised and warrant further investigation.

\subsubsection{The Regulation IL-10 by Cytokine Signalling}

In contrast to what is known about TCR signals promoting IL-10 production, there is a large body of evidence supporting a role for STAT and SMAD proteins downstream of cytokine receptors in the regulation of IL-10 expression in Th cells, although again this may be tightly linked to the differentiation of each Th cell subset. STAT1 downstream of IL-27 [98, 112, 113], STAT3 downstream of IL-27, IL-21 or IL-6 [98, 99, 114], STAT4 downstream of IL-12 [94] and STAT6 downstream of IL-4 [94] have all been linked to IL-10 production in Th cells (Figure 3c). Furthermore, IL-10 could potentially also enhance its own production in $\mathrm{T}$ cells through the activation of STAT3, as previously shown in macrophages [24]. However, it is important to note these functional studies use STAT deficient T cells that are not responsive to the cytokines and thus unable to differentiate into each discrete Th cell subset. Direct binding of the various STATs to the IllO locus has recently been demonstrated for STAT4 in intron 4 in Th1 cells and STAT6 in the promoter region in Th2 cells (Figure 2c), where it is thought to facilitate the acquisition of the activating $\mathrm{H} 3 \mathrm{~K} 4 \mathrm{me} 3$ and loss of the repressive $\mathrm{H} 3 \mathrm{~K} 27 \mathrm{me} 3$ histone marks, thus increasing the accessibility of the $I l 10$ gene locus to transcription factors [16]. In Th17 cells, STAT3 has been shown to bind in an intron 4 in the $I l 10$ gene locus [9] (Figure 2c), although its role in the remodelling of the $I l 10$ gene locus is yet to be determined.

SMADs downstream of TGF- $\beta$ signalling have been shown to regulate IL-10 production in Th cells, albeit at the expense of inhibiting Th1 and Th2, but not Th17 differentiation [94]. In particular, SMAD4 has been shown bind and transactivate the $I l 10$ gene promoter in Th1 but not in 
Th2 cells [115] (Figure 2d), while SMAD3 together with GATA3 has been shown to positively regulate IL-10 production in response to TGF- $\beta$ in a Th2 cell line [116].

\subsubsection{The Role of T Helper Cell Master Regulators in IL-10 Regulation}

Given the role of master regulators in the differentiation of Th cell subsets, to which the production of IL-10 is tightly coupled, it is possible that IL-10 production in Th cells is further regulated by the lineage specific master regulator transcription factors induced mainly downstream of the STAT signalling but also of TCR. Recent genome wide studies of Th cells following the binding of p300, a marker of active enhancers, in wild type versus STAT deficient Th cells transfected with lineage specific master regulators, have identified a small subset of enhancers that are regulated directly by GATA3 [117] and to a lesser extent also by TBET [117] and ROR $\gamma \mathrm{t}$ [118]. Namely, overexpression of GATA3 in STAT6 deficient Th2 cells resulted in the recovery of half of the Th2-specific STAT6 dependent p300 binding sites including many in the Il4 gene locus [117]. Similarly, overexpression of Tbet in STAT4 deficient Th1 cells resulted in the recovery of only about a quarter of the Th1specific STAT4 dependent p300 binding sites including many in the Ifng gene locus [117]. The fact that GATA3 binding can precede enhancer activation in developing thymocytes [119] does suggest that it may function as a pioneer-like factor at certain genetic loci. For example in Th2 cells, GATA3 has been shown to drive the expression of IL-4 by both mediating the remodelling of the Il4 gene locus [120, 121] and transactivation of its promoter [90]. GATA3 also binds and facilitates remodelling of the $I l 10$ gene locus, but it does not transactivate the $I l 10$ promoter [95, 96] (Figure 2d). It remains to be determined whether GATA3 acts as a true pioneer-like transcription factor or whether its action is aided by other factors in order for it to mediate the remodelling of the $I l 10$ gene locus. Furthermore, the fact that GATA3 alone is not able to transactivate the 1110 promoter and is not required for IL-10 production in differentiated Th2 cells [97] illustrates the need for additional factors that promote $I l 10$ gene expression in differentiated Th2 cells. Importantly, GATA3 is only expressed to a high level in Th2 cells, implying that other mechanisms are likely to regulate IL-10 production in the different Th cell subsets that express no or low levels of GATA3. Since both TBET and ROR $\gamma$ t can, similarly to GATA3, regulate a subset of genes independently of the STAT proteins it would be interesting to know whether they can also alter the accessibility of the $I l 10$ gene locus in addition to the hallmark cytokines in Th1 and Th17 cells.

\subsubsection{The Role of Other Transcription factors in IL-10 Regulation}


Although originally described as a Th2 specific transcription factor [122], c-MAF expression is detectable in all the different Th cells subsets, where its expression has been shown to correlate with the levels of IL-10 [94]. In Th2 cells, c-MAF is thought to direct the expression of IL-4 by binding to a c-MAF responsive element (MARE) in the proximal promoter of the $I l 4$ gene [122], the action of which has further been shown to be augmented by IRF4/NFAT1 [123] and AP-1 (JunB) [124]. However, c-MAF alone is thought not to be able to transactivate the $I l 10$ gene promoter [125]. It is yet to be determined whether c-MAF in combination with other factors such as NFAT or AP-1, similarly to their role in the regulation of IL-4, can also regulate IL-10 production, both of which have been shown to bind the $I l 10$ gene locus as discussed above. The expression of c-MAF in Th1 cells is driven by IL-12, however, the role of c-MAF in regulating IL-10 is only correlative whereby the expression of c-MAF decreases together with IL-10 upon treatment with a MEK inhibitor that abrogates ERK activation [94]. Furthermore, it is unclear whether ERK activation is induced downstream of the TCR via Ras, or of IL-12R via TPL-2 [94, 126], or both. In the so called ' $\operatorname{Tr} 1$ ' cells, $\mathrm{CD}^{+}{ }^{+} \mathrm{T}$ cells that co-secrete IFN- $\gamma$ and IL-10 differentiated in vitro in the presence of IL-27 or IL-27 and TGF- $\beta \square[127]$, c-MAF together with AHR have been implicated to play a role in the positive regulation of IL-10 production [128]. As such, knocking down c-MAF or AHR in 'Tr1' cells has been shown to correlate with a decrease in IllO mRNA expression and both have been demonstrated to bind and synergistically transactivate the $I l 10$ gene promoter [128] (Figure 2d). The induction of c-MAF in the 'Tr1' setting is thought to be further regulated by IL-21 and possibly by inducible T cell costimulator (ICOS) since both IL-21 and ICOS deficient T cells show reduced IL-10 production and c-MAF expression [129]. Of note, both IL-27 [130] and IL-21 [131] are thought to also activate ERK. Downstream of TGF- $\beta$ signalling c-MAF has been shown to play a role in the differentiation programme of Th17 cells [132], where it is primarily thought to act as a repressor of proinflammatory gene expression e.g. of Rora, Runx1, Il1r1, Ccr6, and Tnf but where it can also act as an inducer of genes involved in the attenuation of inflammation, including of $I l 10$ [118]. c-MAF has been further shown to positively regulate IL-10 (and possibly IL-17) in Th17 cells, but to have negative effect on IL-22 production, as demonstrated using retroviral transduction and siRNA knock down assays [132]. In Th17 cells, c-MAF has additionally been shown to bind and transactivate the $I l 10$ gene promoter in a luciferase reporter assay [99] (Figure 2d). Taken together, these findings indicate that c-MAF could act as a common transcriptional regulator of IL10 in different immune cell types, as suggested by both the Th cell and macrophage studies described above. However, at least in Th2 cells, it is unclear whether c-maf is involved in differentiation rather than IL-10 production per se. 
The transcriptional repressor E4 promoter-binding protein 4 (E4BP4) encoded by the Nfil3 gene has recently been shown to play a role in positively regulating the production of IL-10 in Th1 and Th2 cells independently of their hallmark cytokines IFN- $\gamma$ and IL-4, respectively [133] (Figure 2c). E4BP4 has been shown to bind to intron 4 and to 3' UTR at the $I l 10$ gene locus in Th2 cells and, owing to the decrease in histone acetylation in Th2 cells from $N f i l 3^{--}$mice, E4BP4 is thought to regulate the permissive status of the $I l 10$ gene locus [133]. Specifically, E4BP4 has been shown to increase $I l 10$ gene expression in a GATA3-independent manner, as demonstrated by retroviral transduction studies in $\mathrm{Nfil}^{-/}$and Gata3 conditional knockout cells [133]. Thus, E4BP4 could be a dominant factor responsible for epigenetic regulation controlling accessibility of the $1 l 10$ gene locus in Th1 cells, akin to GATA3 in Th2 cells. Although it is not yet known which signalling pathways lead to the induction of Nfil3 expression in T cells, in macrophages Nfil3 is an IL-10 responsive gene [134]. Of note, overexpression of E4BP4 does not allow Th17 differentiation [118], implying that other mechanisms must operate to allow IL-10 production in Th17 cells. Moreover, $\mathrm{Nfil}^{-/-}$ mice develop mild diarrhoea reminiscent of colitis observed in $I l 10^{-/}$animals [133]. It is not clear, however, whether this is due to the possible lack of IL-10 in T cells or myeloid cells, a Th cell imbalance, or all of these.

PR domain zinc finger protein 1 (BLIMP-1) encoded by the Prdml gene is a transcriptional repressor induced downstream of the TCR that has also been shown to positively regulate IL-10 production in $\mathrm{CD}^{+} \mathrm{T}$ cells, as demonstrated by decreased IL-10 production in Prdm $1^{f l f l}$ Lck Cre ${ }^{-}$ $\mathrm{CD}^{+} \mathrm{T}$ cells, which in vivo is accompanied by pathology and increased inflammation [135]. However, in addition to the observed decrease in IL-10 production, PrdmI ${ }^{\text {flffl }}$ Lck Cre CD4 $^{+} \mathrm{T}$ cells produce increased amounts of IL-2 and IFN- $\gamma \square \square \square \square \square \square \square \square \square$ heir IL-4 production is not affected and the effect on IL-17 production is unknown [135]. BLIMP-1 downstream of IL-27 has further been demonstrated to mediate IL-10 induction in $\mathrm{CD}^{+}$[136] and $\mathrm{CD}^{+} \mathrm{T}$ cells [137]. IL-10 production by $\mathrm{CD}^{+}$Treg cells is also regulated by BLIMP-1, primarily by its synergistic effect with IRF4 on histone acetylation at the Ill0 gene promoter [138]. However, the molecular mechanism of how BLIMP-1 regulates IL-10 production in Th cells is not known. Hence the severe colitis that is observed in Prdm flffl Lck Cre mice may be due to the collective effect of defective thymic output, decreased Treg cell IL-10 production and/or excessive effector T cell function [135].

Of note, BLIMP-1 expression is regulated by B-cell lymphoma 6 (BCL-6), itself a transcriptional repressor typically involved in the establishment of $\mathrm{T}$ follicular helper (Tfh) cell identity [139-141]. Similarly to what is known about BCL-6 regulation in B cells, the action of BCL-6 in T cells is in turn suppressed by BLIMP-1 [140]. BCL-6 expression is driven by IL-6 and IL-21 and it functions 
mainly by inhibiting the expression and/or function of TBET, GATA3 and ROR $\gamma \mathrm{t}$ master regulator transcription factors thus suppressing the Th1, Th2 and Th17 differentiation programmes, respectively, while concurrently inducing the expression Tfh cell related genes [142, 143]. In view of the reciprocal regulation of BLIMP-1 and BCL-6, it is possible that the role of BLIMP-1 in IL-10 regulation is indirect via the repression of BCL-6 and subsequent upregulation of GATA3 [144].

\subsubsection{The regulation of $I L-10$ by Notch Signalling}

In addition to the TCR and cytokine signals, signalling via Notch following interaction with ligands induced on macrophages and DCs by pathogen-derived signals have been shown to have an impact on the differentiation of $\mathrm{CD}^{+}{ }^{+} \mathrm{Th}$ cells as well as their production of IL-10 (Figure 3c). In particular, the engagement of Delta-like Notch ligands (DLL) has been shown to favour the development of Th1 cells, while ligation of Jagged preferentially leads to Th2 cell differentiation [145]. DLL-1 and DLL-4 Notch ligands have further been shown to induce IL-10 but have little effect on IFN- $\gamma$ production in Th1 cells [146]. Of interest, Jagged1, typically associated with inducing IL-4 production via Notch, has paradoxically been identified as the ligand of CD46 [147] driving the production of IL-10 in human T cells that co-secrete IFN- $\gamma$ [148]. However, the exact molecular mechanisms of IL-10 regulation by Notch signalling are not yet known and warrant further investigation.

\subsubsection{Negative Regulators of IL-10 Production}

Similarly to macrophages and DCs, negative mechanisms of IL-10 regulation have also been identified in Th cells.

E26 transformation-specific 1 (ETS-1) is a member of the ETS family of transcription factors, the expression of which is high in resting $\mathrm{T}$ cells but decreases following their activation [149]. Of note, ETS-1 can be further regulated at a post-transcriptional level by ERK [150], although it is not known whether this is the case in T cells. ETS-1 has been shown to negatively regulate IL-10 production in Th1 and Th2 cells, as demonstrated by enhanced IL-10 in Ets $1^{-/-} \mathrm{CD} 4^{+} \mathrm{T}$ cells stimulated under Th1 and Th2 skewing conditions, though the effect of ETS-1 deficiency on the hallmark cytokines has not been investigated [151]. Of note, ETS-1 has previously been shown to positively regulate IFN- $\gamma$ together with TBET [152]. ETS-1 has been to shown to downregulate the expression of IL-10 in Th1 cells via its interaction and recruitment of HDAC1 to HSS $-0.12,+1.65$ 
and $+2.98 \mathrm{~kb}$ at the $I l 10$ gene locus, thus maintaining its relatively closed conformation [151] (Figure 2c).

PU.1, another member of the ETS family, is expressed specifically in Th2 cells where it inhibits the production of Th2 hallmark cytokines including IL-10 by interfering with DNA binding of the master regulator GATA3, although a direct effect PU.1 on the $I l 10$ gene locus has not been reported [153]. In addition to GATA3, PU.1 also complexes with IRF4, a transcription factor correlating with high levels of IL-10 expression in Th2 cells, thus preventing the ability of IRF4 to bind and to transactivate the $I l 10$ gene promoter [11].

In summary, the above studies indicate that the activity of transcription factors downstream of the TCR, cytokine signalling and other environmental cues regulate the production of IL-10 at multiple levels ranging from increasing the accessibility of the $I l 10$ gene locus to cooperative binding of transcription factors. This allows the assembly of transcription factor complexes at discrete sites along the $I l 10$ gene locus which likely act as platforms to integrate TCR and cytokine driven signals allowing the transcription of the $I l 10$ gene in a context specific manner. However, the components of the transcription factor complexes and their temporal recruitment to the $I l 10$ gene locus during the differentiation of the various Th cell subsets remain unclear and require further investigation. However, the tight relationship between Th cell differentiation versus IL-10 production poses a challenge in the future studies in this field. Furthermore, it will be important to determine what are the common or cell type specific requirements for IL-10 production in the Th cell subsets. Ultimately, these studies will need to be recapitulated in human cells, as most of the data to date has been generated using mouse as a model organism.

\subsection{Postranscriptional regulation of IL-10}

Post-transcriptional control of cytokine production is a key step for the regulation of the amount of cytokines produced by cells of the immune system [154, 155] (Figure 1). This layer of regulation is critical to ensure that the rapid transcription of cytokines in response to an initial stimulus, such as microbial infection, is also rapidly turned off to avoid excessive pro-inflammatory cytokine production likely resulting in tissue damage, or the development of chronic infection in the case of an anti-inflammatory cytokine such as IL-10. One of the first pieces of evidence of posttranscriptional regulation of $I l 10$ expression came from studies of the 3'UTR of the IllO mRNA, which showed the existence of AU rich elements (AREs), capable of mediating mRNA decay in a 
lymphocyte cell line [156]. Another study, however, concluded that the same destabilizing effect of the 3'UTR of IllO mRNA was not observed in RAW 264.7 macrophages [157]. AREs are found in many cytokine 3'UTRs and mark short-lived mRNA, as they recruit various ARE-binding proteins that increase or decrease mRNA stability [154]. The ARE-binding protein that was identified in a genome wide analysis to target Ill0 mRNA is tristetraprolin (TTP) [158]. TTP also promotes the rapid decay of other cytokine mRNAs, including that of tumour necrosis factor (TNF) [159], IL-6 [160] and granulocyte-monocyte colony stimulating factor (GM-CSF) [161], by initiating the assembly of RNA decay machinery thus causing the elimination of bound mRNAs $[162,163]$. In line with a role for TTP in regulating $I l 10$ mRNA stability, the half-life of $I l 10 \mathrm{mRNA}$ in TLR 4 stimulated macrophages was increased in the absence of this molecule [158, 164]. Consequently, in the absence of TTP the amount of IL-10 produced by TLR 4 stimulated macrophages was found to be higher [164]. More importantly, higher IL-10 levels were also described in vivo in the serum of LPS-treated mice where TTP was ablated from myeloid cells [165]. However, such differences in IL-10 production were not found in TLR 4 stimulated TTP deficient DCs [166], potentially due to increased p38 activity in these cells [167]. Indeed, TTP is negatively regulated by the MAP kinase p38 [168-171], which although needed for TTP expression, also restrains the mRNA destabilizing activity of TTP [172]. Although the impact of p38 control of TTP-mediated mRNA destabilization varies with target mRNAs, in the case of IL-10, the inhibition of p38 activation allows for elevated TTP activity and thus enhanced TTP-mediated mRNA decay [171]. In a recent study, the activity of p38 during the inflammatory response was shown to qualitatively and temporally control TTP activity, thus leading to a timely induction of cytokine mRNA decay [165]. This temporal control of TTP by p38 is influenced by different mechanisms including by TRIF signalling, as shown by comparing the activity of p38 activity and the IL-10 mRNA decay in macrophages stimulated through TLR 2 or TLR 4 (Teixeira-Coelho et al, in press). Although less studied than TTP, the RNA-binding protein ARE/poly(U) binding degradation factor 1 (AUF1) is also known to bind to the 3'UTR of the IL-10 mRNA. Diminished levels of AUF1 correlated with increased half-life of the IL-10 mRNA in a melanoma cell line [173]. More recently, the translocation of AUF1 from the nucleus to the cytosol of TLR 4 stimulated macrophages was found to be regulated by DUSP1 [174]. Consequently, in the absence of DUSP1, both $I l 10$ mRNA stability and IL-10 secretion were increased [175].

IL-10 has been shown itself to regulate the stability of cytokine mRNAs, including its own, in TLR 4 stimulated blood monocytes [176]. More recently, this effect of IL-10 was found to be dependent on TTP. In addition to being a target of TTP, IL-10 is itself an activator of TTP, by increasing TTP expression and reducing late p38 activity $[164,177]$. Thus, in situations when IL-10 is being 
produced, TTP is activated and a post-transcriptional program for cytokine gene regulation is initiated, mediated by IL-10 induction of mRNA decay. It is possible that this mechanism results in limiting IL-10 translation, thus helping in guaranteeing the appropriate balance of the immune response.

Additionally to the 3'UTRs that control the mRNA stability and decay rates, 5'UTR regions are also linked to post-transcriptional gene regulation by mediating the binding rate of mRNA to the ribosomal 40S subunit, thus controlling the mRNA translation [178]. Two alternative variants of the 5'UTR sequences were found in Ill0 mRNA synthesized after TLR 4 stimulation of blood cells, suggesting that modulation of IL-10 protein translation may also be implicated in the network of post-transcriptional mechanisms regulating IL-10 [179].

MicroRNAs (miRNA) have also been shown to contribute to the post-transcriptional mechanisms regulating TLR signalling and subsequent cytokine production, including that of IL-10 [180]. For example, hsa-miRNA-106a binds to the 3'UTR of the IL-10 mRNA and negatively regulates its expression in different cell lines [181]. Also, miRNA-4661 was shown to upregulate TLR-induced IL-10 expression in macrophages by antagonizing TTP-mediated $I l 10$ mRNA degradation and extending the half-life of $I l 10$ mRNA [182]. MiRNA-21 induced upon TLR 4 stimulation targeted the effector molecule programmed cell death 4 (PDCD4) and promoted IL-10 production [183].

Thus, a growing body of evidence clearly demonstrates that IL-10 production by immune cells is controlled at the post-transcriptional level along with many other cytokines. Since the majority of the studies have been performed in TLR-activated macrophages, it will be interesting to study these potential mechanisms in other immune cells. For example, in $\mathrm{CD}^{+} \mathrm{T}$ cells, p38 was found to be involved in regulating the stability of IL-4 and IL-5 mRNAs [184], but such studies are lacking in relation to IL-10.

\subsection{Concluding remarks}

IL-10 mediates the fine balance between immunosuppression and immunopathology in a number of settings. Therefore, a thorough understanding of the molecular mechanisms that regulate the expression of this cytokine is crucial for the design of immune intervention strategies. The subject of IL-10 regulation is complicated by the fact that IL-10 can be expressed by almost all cells within both the innate and adaptive immune systems, despite the fact that each cell type responds to 
different stimuli. This complexity is further compounded by the numerous positive and negative regulatory networks which integrate to determine the final level of IL-10 production.

In macrophages and DCs, although several mechanisms have been identified which regulate the production of IL-10, most studies focus on single PRR stimuli, whereas pathogens likely activate multiple PRRs. As such, how the signals from different PRRs co-operate to modulate IL-10 production versus the production of different proinflammatory cytokines remain only partially understood. Additionally, the production of IL-10 in response to damage associated molecular patterns (DAMP) has to date not been investigated. These studies would provide a better understanding of the regulation of IL-10 in the context of infection and sterile inflammation. In addition, the mechanisms controlling the distinct levels of IL-10 produced by the different myeloid populations, for example the relatively higher level of IL-10 production by macrophages compared to DCs, are poorly defined. Fully investigating whether the signalling pathways induced by the same TLRs are fundamentally different in macrophages, DCs and myeloid populations from distinct anatomical locations, or if the chromatin state of the $I l 10$ locus is different between these cell types would greatly enhance our understanding of how IL-10 is regulated.

In $\mathrm{T}$ cells, several signalling pathways and downstream transcription factors regulating IL-10 have been identified in the different Th cell subsets. However, the ultimate challenge lays in distinguishing whether these factors are truly a requirement for IL-10 expression as opposed to a requirement for Th cell differentiation, or both. Furthermore, many of the studies to date concentrate on a single Th cell subset. A concurrent analysis of the all the subsets would allow us to determine whether there are common or Th cell type specific factors for IL-10 production in the different Th cell subsets. Lastly, owing to the heterogeneity within each of the Th cell populations with respect to hallmark cytokine as well as IL-10 production, it would be important to investigate these separately in order to obtain more meaningful results.

Therefore, for all cell types, including those currently less studied but known to produce IL-10, such as mast cells, B cells or regulatory T cells, the future challenge is to decipher the complex IL10 regulatory networks including the temporal recruitment of transcription factors and their hierarchies of binding to the $I l 10$ gene locus. The use of genome-wide, high-throughput, high resolution and bioinformatic approaches will complement traditional molecular and biochemical methods and be key to gaining a better understanding of IL-10 regulation in the different immune cell types. Finally, it will be important to identify the immune scenarios in which these various 
factors regulate IL-10 production in vivo in order to use this knowledge in the fine-tuning of immune intervention strategies.

\section{Acknowledgements}

At NIMR, we thank B. Seddon, C. Sinclair and S. Ley for discussions, J. Brock from PhotoGraphics for the generation of figures and C. Whicher for critical reading of the manuscript. MS is a FCT Associate Investigator. AOG, LG, AH are funded by UK MRC (U117565642); A.O.G. is also funded by Imperial College, National Heart and Lung Institute; AOG \& LG are also funded by ERC-2011-AdG, 294682-TB-PATH; MS is funded by Fundação para a Ciência e Tecnologia, Portugal and co-funded by Programa 73 Operacional Regional do Norte (ON.2 - O Novo Norte), Quadro de Referência Estratégico Nacional 74 (QREN), through the Fundo Europeu de Desenvolvimento Regional (FEDER). 


\section{Figure Legends:}

\section{Figure 1: Concepts of gene regulation.}

Mechanisms governing gene expression operate at several levels including chromatin accessibility, active regulation of transcription as well as post-transcriptional regulation. Within chromosomes, DNA is wrapped around octamers of core histones forming nucleosomes, the basic units of eukaryotic chromatin. Multiple nucleosomes are then arranged along the DNA as 'beads on a string' (accessible euchromatin). The compaction of chromatin into $30 \mathrm{~nm}$ fibres is achieved upon the addition of linker histones to nucleosomes giving rise to inaccessible, transcriptionally inactive heterochromatin. Depicted are features governing the accessibility of chromatin including DNA methylation, histone modifications or DNase hypersensitive sites (HSS). Open chromatin allows for transcription factor binding to gene regulatory elements such as distal regulatory elements (DRE) or promoters and initiation of gene expression by RNA polymerase. Once transcribed, mRNA can further be subject to post-transcriptional regulation at the 3'UTR by AU rich (ARE)-binding proteins that increase or decrease mRNA stability by preventing or aiding its degradation by RNA decay machinery, respectively.

\section{Figure 2: A diagram of mouse chromosome 1 showing the $I l 10$ gene locus.}

(a) IllO gene and its neighbours, horizontal arrows (blue) depict orientation of gene expression. (b) Detail of DNA surrounding the $I l 10$ gene locus, vertical arrows denote HSS sites present equally in Th1 and Th2 cells (black) or more prominently in Th2 cells (green) aligned against Vista plot of the murine sequence versus human homology, pink peaks denote CNS. (c) Il10 gene locus and its regulatory elements again aligned against Vista plot of the murine sequence versus human homology, pink peaks denote CNS, purple peaks denote exons and turquoise peak denotes 3' UTR. Arrows denote HSS sites with their relative position to the IllO TSS indicated, and the cell type in which they have been detected depicted (macrophage, DC, Th1 and Th2), note that HSS -0.12 and $+6.45 \mathrm{~kb}$ have been shown to be more prominent in Th2 over Th1 cells. The binding sites of transcription factors that have been shown to regulate $I l 10$ gene expression in the different cell types (indicated by different colour borders) are also shown. (d) Ill0 gene proximal promoter, depicts further binding sites of transcription factors regulating $I l 10$ gene expression.

Figure 3: Signals that induce IL-10 expression in representative cells of the innate (macrophages and DCs) and adaptive (Th cells) immune system.

(a) The expression of $I l 10$ is induced by signals downstream of PRRs, such as TLRs, in macrophages and mDCs. Downstream of TLR ligation the recruitment of the adaptor molecules 
MYD88 and TRIF are critical for the activation of downstream signalling pathways. Of these, ERK and p38 MAP kinases, the PI(3)K-AKT pathway and the NF- $\kappa$ B pathway have been shown to have roles in the induction of $I l 10$ gene expression. Importantly, several of these pathways also mediate the expression of pro-inflammatory cytokines. Non-TLR PRRs can also induce IL-10 production. An example of this is Dectin-1, which is expressed mainly on DCs and induces IL-10 production via a SYK and ERK dependent pathway. Ill0 expression is further modulated by signals induced by surrounding cytokines such as type I IFN and IL-10 itself which promote IL-10 production, and IFN- $\gamma$ which inhibits IL-10 production through the inhibition of MAP kinase and PI(3)K-AKT pathways. (b) The TPL-2/ERK pathway induces IL-10 production which positively feeds back to upregulate TPL-2. In contrast, the TPL-2/ERK pathway negatively regulates IFN- $\beta$ production, itself a positive regulator of IL-10. The negative regulation of IFN- $\beta$ by this pathway is both dependent and independent of IL-10 production. This complex molecular network also includes the regulation of pro-inflammatory cytokines e.g. TNF and IL-12, which are positively and negatively regulated by the TPL-2/ERK pathway, respectively. (c) The expression of IL-10 in CD4 ${ }^{+} \mathrm{T}$ cells is initiated by signalling downstream of the TCR and costimulatory molecules such as CD28 and involves the MAP kinase ERK, the calcineurin-NFAT and the NF- $\kappa B$ pathways, amongst others. It is further modulated by signals downstream of cytokine receptors via STAT or SMAD proteins that are also critical for the differentiation of naïve $\mathrm{CD} 4^{+}$cells into the different Th cell subsets. At least in Th2 cells, IL-10 production is further regulated by the lineage specific master regulator transcription factor GATA3 induced mainly downstream of the STAT6 signalling but also of TCR. In addition to the TCR and cytokine signals, signalling through Notch ligands induced on macrophages and DCs by pathogen-derived signals has an impact on the differentiation of CD4 ${ }^{+} \mathrm{Th}$ cells as well as their IL-10 production. 


\section{References}

1. Moore, K.W., et al., Interleukin-10 and the interleukin-10 receptor. Annual Review of Immunology, 2001. 19: p. 683-765.

2. Saraiva, M. and A. O'Garra, The regulation of $I L-10$ production by immune cells. Nat Rev Immunol, 2010. 10(3): p. 170-81.

3. Zhu, J., H. Yamane, and W.E. Paul, Differentiation of effector CD4 T cell populations (*). Annu Rev Immunol, 2010. 28: p. 445-89.

4. Jiang, C. and B.F. Pugh, Nucleosome positioning and gene regulation: advances through genomics. Nat Rev Genet, 2009. 10(3): p. 161-72.

5. Jenuwein, T. and C.D. Allis, Translating the histone code. Science, 2001. 293(5532): p. 1074-80.

6. Lenhard, B., A. Sandelin, and P. Carninci, Metazoan promoters: emerging characteristics and insights into transcriptional regulation. Nat Rev Genet, 2012. 13(4): p. 233-45.

7. Kim, J.M., et al., Structure of the mouse IL-10 gene and chromosomal localization of the mouse and human genes. J Immunol, 1992. 148(11): p. 3618-23.

8. Frazer, K.A., et al., VISTA: computational tools for comparative genomics. Nucleic Acids Res, 2004. 32(Web Server issue): p. W273-9.

9. Li, P., et al., BATF-JUN is critical for IRF4-mediated transcription in T cells. Nature, 2012. 490(7421): p. 543-6.

10. Lee, C.G., et al., A distal cis-regulatory element, CNS-9, controls NFAT1 and IRF4mediated IL-10 gene activation in T helper cells. Mol Immunol, 2009. 46(4): p. 613-21.

11. Ahyi, A.N., et al., IFN regulatory factor 4 regulates the expression of a subset of Th2 cytokines. J Immunol, 2009. 183(3): p. 1598-606.

12. Jones, E.A. and R.A. Flavell, Distal enhancer elements transcribe intergenic RNA in the IL10 family gene cluster. J Immunol, 2005. 175(11): p. 7437-46.

13. Wang, Z.Y., et al., Regulation of IL-10 gene expression in Th2 cells by Jun proteins. J Immunol, 2005. 174(4): p. 2098-105.

14. Saraiva, M., et al., Identification of a macrophage-specific chromatin signature in the IL10 locus. J Immunol, 2005. 175(2): p. 1041-6.

15. Im, S.H., et al., Chromatin-level regulation of the IL10 gene in T cells. J Biol Chem, 2004. 279(45): p. 46818-25.

16. Wei, L., et al., Discrete roles of STAT4 and STAT6 transcription factors in tuning epigenetic modifications and transcription during Thelper cell differentiation. Immunity, 2010. 32(6): p. 840-51.

17. Boonstra, A., et al., Macrophages and myeloid dendritic cells, but not plasmacytoid dendritic cells, produce IL-10 in response to MyD88- and TRIF-dependent TLR signals, and TLR-independent signals. J Immunol, 2006. 177(11): p. 7551-8.

18. Kaiser, F., et al., TPL-2 negatively regulates interferon-beta production in macrophages and myeloid dendritic cells. Journal of Experimental Medicine, 2009. 206(9): p. 186371.

19. Ito, T., et al., Specialization, kinetics, and repertoire of type 1 interferon responses by human plasmacytoid predendritic cells. Blood, 2006. 107(6): p. 2423-31.

20. Gerber, J.S. and D.M. Mosser, Reversing lipopolysaccharide toxicity by ligating the macrophage Fc gamma receptors. J Immunol, 2001. 166(11): p. 6861-8.

21. Edwards, A.D., et al., Microbial recognition via Toll-like receptor-dependent and independent pathways determines the cytokine response of murine dendritic cell subsets to CD40 triggering. J Immunol, 2002. 169(7): p. 3652-60. 
22. Chang, E.Y., et al., Cutting edge: involvement of the type I IFN production and signaling pathway in lipopolysaccharide-induced IL-10 production. J Immunol, 2007. 178(11): p. 6705-9.

23. $\mathrm{Hu}, \mathrm{X}$., et al., IFN-gamma suppresses IL-10 production and synergizes with TLR2 by regulating GSK3 and CREB/AP-1 proteins. Immunity, 2006. 24(5): p. 563-74.

24. Staples, K.J., et al., IL-10 induces IL-10 in primary human monocyte-derived macrophages via the transcription factor Stat3. J Immunol, 2007. 178(8): p. 4779-85.

25. Cao, S., et al., The protooncogene c-Maf is an essential transcription factor for IL-10 gene expression in macrophages. J Immunol, 2005. 174(6): p. 3484-92.

26. Kawai, T. and S. Akira, The role of pattern-recognition receptors in innate immunity: update on Toll-like receptors. Nat Immunol, 2010. 11(5): p. 373-84.

27. Kadowaki, N., et al., Subsets of human dendritic cell precursors express different toll-like receptors and respond to different microbial antigens. J Exp Med, 2001. 194(6): p. 8639.

28. Jarrossay, D., et al., Specialization and complementarity in microbial molecule recognition by human myeloid and plasmacytoid dendritic cells. Eur J Immunol, 2001. 31(11): p. 3388-93.

29. Edwards, A.D., et al., Toll-like receptor expression in murine DC subsets: lack of TLR7 expression by CD8 alpha+ DC correlates with unresponsiveness to imidazoquinolines. Eur J Immunol, 2003. 33(4): p. 827-33.

30. Agrawal, S., et al., Cutting edge: different Toll-like receptor agonists instruct dendritic cells to induce distinct Th responses via differential modulation of extracellular signalregulated kinase-mitogen-activated protein kinase and c-Fos. J Immunol, 2003. 171(10): p. 4984-9.

31. Hacker, H., et al., Specificity in Toll-like receptor signalling through distinct effector functions of TRAF3 and TRAF6. Nature, 2006. 439(7073): p. 204-7.

32. Chi, H., et al., Dynamic regulation of pro- and anti-inflammatory cytokines by MAPK phosphatase 1 (MKP-1) in innate immune responses. Proc Natl Acad Sci U S A, 2006. 103(7): p. 2274-9.

33. Reid, D.M., N.A. Gow, and G.D. Brown, Pattern recognition: recent insights from Dectin-1. Curr Opin Immunol, 2009. 21(1): p. 30-7.

34. Dennehy, K.M., et al., Reciprocal regulation of IL-23 and IL-12 following co-activation of Dectin-1 and TLR signaling pathways. Eur J Immunol, 2009. 39(5): p. 1379-86.

35. Banerjee, A., et al., Diverse Toll-like receptors utilize Tpl2 to activate extracellular signalregulated kinase (ERK) in hemopoietic cells. Proc Natl Acad Sci U S A, 2006. 103(9): p. 3274-9.

36. Dillon, S., et al., A Toll-like receptor 2 ligand stimulates Th2 responses in vivo, via induction of extracellular signal-regulated kinase mitogen-activated protein kinase and c-Fos in dendritic cells. J Immunol, 2004. 172(8): p. 4733-43.

37. Yi, A.K., et al., Role of mitogen-activated protein kinases in CpG DNA-mediated IL-10 and IL-12 production: central role of extracellular signal-regulated kinase in the negative feedback loop of the CpG DNA-mediated Th1 response. J Immunol, 2002. 168(9): p. 4711-20.

38. McNab, F.W., et al., TPL-2-ERK1/2 signaling promotes host resistance against intracellular bacterial infection by negative regulation of type I IFN production. J Immunol, 2013. 191(4): p. 1732-43.

39. Dumitru, C.D., et al., TNF-alpha induction by LPS is regulated posttranscriptionally via a Tpl2/ERK-dependent pathway. Cell, 2000. 103(7): p. 1071-83.

40. Gantke, T., S. Sriskantharajah, and S.C. Ley, Regulation and function of TPL-2, an IkappaB kinase-regulated MAP kinase kinase kinase. Cell Res, 2011. 21(1): p. 131-45. 
41. Aman, M.J., et al., Interferon-alpha stimulates production of interleukin-10 in activated CD4+ T cells and monocytes. Blood, 1996. 87(11): p. 4731-6.

42. Pattison, M.J., K.F. Mackenzie, and J.S. Arthur, Inhibition of JAKs in Macrophages Increases Lipopolysaccharide-Induced Cytokine Production by Blocking IL-10-Mediated Feedback. J Immunol, 2012. 189(6): p. 2784-92.

43. Mayer-Barber, K.D., et al., Innate and adaptive interferons suppress $I L$-1alpha and IL1 beta production by distinct pulmonary myeloid subsets during Mycobacterium tuberculosis infection. Immunity, 2011. 35(6): p. 1023-34.

44. Slack, E.C., et al., Syk-dependent ERK activation regulates IL-2 and IL-10 production by DC stimulated with zymosan. European Journal of Immunology, 2007. 37(6): p. 160012.

45. Dillon, S., et al., Yeast zymosan, a stimulus for TLR2 and dectin-1, induces regulatory antigen-presenting cells and immunological tolerance. J Clin Invest, 2006. 116(4): p. 916-28.

46. Karin, M., Z. Liu, and E. Zandi, AP-1 function and regulation. Curr Opin Cell Biol, 1997. 9(2): p. 240-6.

47. Rogers, N.C., et al., Syk-dependent cytokine induction by Dectin-1 reveals a novel pattern recognition pathway for $C$ type lectins. Immunity, 2005. 22(4): p. 507-17.

48. Lucas, M., et al., ERK activation following macrophage FcgammaR ligation leads to chromatin modifications at the IL-10 locus. J Immunol, 2005. 175(1): p. 469-77.

49. Zhang, X., J.P. Edwards, and D.M. Mosser, Dynamic and transient remodeling of the macrophage IL-10 promoter during transcription. J Immunol, 2006. 177(2): p. 1282-8.

50. Brightbill, H.D., et al., A prominent role for Sp1 during lipopolysaccharide-mediated induction of the IL-10 promoter in macrophages. J Immunol, 2000. 164(4): p. 1940-51.

51. Tone, M., et al., IL-10 gene expression is controlled by the transcription factors Sp1 and Sp3. J Immunol, 2000. 165(1): p. 286-91.

52. Ramirez-Carrozzi, V.R., et al., $A$ unifying model for the selective regulation of inducible transcription by CpG islands and nucleosome remodeling. Cell, 2009. 138(1): p. 114-28.

53. Foey, A.D., et al., Regulation of monocyte $I L-10$ synthesis by endogenous $I L-1$ and TNFalpha: role of the $p 38$ and p42/44 mitogen-activated protein kinases. J Immunol, 1998. 160(2): p. 920-8.

54. Jarnicki, A.G., et al., Attenuating regulatory $T$ cell induction by TLR agonists through inhibition of p38 MAPK signaling in dendritic cells enhances their efficacy as vaccine adjuvants and cancer immunotherapeutics. J Immunol, 2008. 180(6): p. 3797-806.

55. Kim, L., et al., p38 MAPK autophosphorylation drives macrophage IL-12 production during intracellular infection. J Immunol, 2005. 174(7): p. 4178-84.

56. Ma, W., et al., The p38 mitogen-activated kinase pathway regulates the human interleukin-10 promoter via the activation of Sp1 transcription factor in lipopolysaccharide-stimulated human macrophages. J Biol Chem, 2001. 276(17): p. 13664-74.

57. Chung, E.Y., et al., Interleukin-10 expression in macrophages during phagocytosis of apoptotic cells is mediated by homeodomain proteins Pbx1 and Prep-1. Immunity, 2007. 27(6): p. 952-64.

58. Ananieva, 0., et al., The kinases MSK1 and MSK2 act as negative regulators of Toll-like receptor signaling. Nat Immunol, 2008. 9(9): p. 1028-36.

59. Platzer, C., et al., Cyclic adenosine monophosphate-responsive elements are involved in the transcriptional activation of the human IL-10 gene in monocytic cells. Eur J Immunol, 1999. 29(10): p. 3098-104.

60. Alvarez, Y., et al., The induction of IL-10 by zymosan in dendritic cells depends on CREB activation by the coactivators CREB-binding protein and TORC2 and autocrine PGE2. J Immunol, 2009. 183(2): p. 1471-9. 
61. Chakrabarti, A., et al., Protein kinase $R$-dependent regulation of interleukin-10 in response to double-stranded RNA. J Biol Chem, 2008. 283(37): p. 25132-9.

62. Martin, M., et al., Role of the phosphatidylinositol 3 kinase-Akt pathway in the regulation of IL-10 and IL-12 by Porphyromonas gingivalis lipopolysaccharide. J Immunol, 2003. 171(2): p. 717-25.

63. Ohtani, M., et al., Mammalian target of rapamycin and glycogen synthase kinase 3 differentially regulate lipopolysaccharide-induced interleukin-12 production in dendritic cells. Blood, 2008. 112(3): p. 635-43.

64. Weichhart, T., et al., The TSC-mTOR signaling pathway regulates the innate inflammatory response. Immunity, 2008. 29(4): p. 565-77.

65. Nandan, D., et al., Myeloid cell IL-10 production in response to leishmania involves inactivation of glycogen synthase kinase-3beta downstream of phosphatidylinositol-3 kinase. J Immunol, 2012. 188(1): p. 367-78.

66. Martin, M., et al., Toll-like receptor-mediated cytokine production is differentially regulated by glycogen synthase kinase 3. Nat Immunol, 2005. 6(8): p. 777-84.

67. Katholnig, K., et al., p38alpha Senses Environmental Stress To Control Innate Immune Responses via Mechanistic Target of Rapamycin. J Immunol, 2013.

68. Benkhart, E.M., et al., Role of Stat3 in lipopolysaccharide-induced IL-10 gene expression. J Immunol, 2000. 165(3): p. 1612-7.

69. Murray, P.J., Understanding and exploiting the endogenous interleukin-10/STAT3mediated anti-inflammatory response. Curr Opin Pharmacol, 2006. 6(4): p. 379-86.

70. Kanters, E., et al., Inhibition of NF-kappaB activation in macrophages increases atherosclerosis in LDL receptor-deficient mice. J Clin Invest, 2003. 112(8): p. 1176-85.

71. Cao, S., et al., NF-kappaB1 (p50) homodimers differentially regulate pro- and antiinflammatory cytokines in macrophages. J Biol Chem, 2006. 281(36): p. 26041-50.

72. Brenner, S., et al., cAMP-induced Interleukin-10 promoter activation depends on CCAAT/enhancer-binding protein expression and monocytic differentiation. J Biol Chem, 2003. 278(8): p. 5597-604.

73. Liu, Y.W., et al., Functional cooperation of simian virus 40 promoter factor 1 and CCAAT/enhancer-binding protein beta and delta in lipopolysaccharide-induced gene activation of IL-10 in mouse macrophages. J Immunol, 2003. 171(2): p. 821-8.

74. Csoka, B., et al., A2A adenosine receptors and C/EBPbeta are crucially required for IL-10 production by macrophages exposed to Escherichia coli. Blood, 2007. 110(7): p. 268595.

75. Kimura, A., et al., Aryl hydrocarbon receptor in combination with Stat1 regulates LPSinduced inflammatory responses. J Exp Med, 2009. 206(9): p. 2027-35.

76. Villagra, A., et al., The histone deacetylase HDAC11 regulates the expression of interleukin 10 and immune tolerance. Nat Immunol, 2009. 10(1): p. 92-100.

77. Krausgruber, T., et al., IRF5 promotes inflammatory macrophage polarization and TH1TH17 responses. Nat Immunol, 2011. 12(3): p. 231-8.

78. Lang, R., et al., Shaping gene expression in activated and resting primary macrophages by IL-10. J Immunol, 2002. 169(5): p. 2253-63.

79. Hammer, M., et al., Control of dual-specificity phosphatase-1 expression in activated macrophages by IL-10. Eur J Immunol, 2005. 35(10): p. 2991-3001.

80. Ziegler-Heitbrock, L., et al., IFN-alpha induces the human IL-10 gene by recruiting both IFN regulatory factor 1 and Stat3. J Immunol, 2003. 171(1): p. 285-90.

81. Guarda, G., et al., Type I interferon inhibits interleukin-1 production and inflammasome activation. Immunity, 2011. 34(2): p. 213-23.

82. Wang, H., et al., The Role of Glycogen Synthase Kinase 3 in Regulating IFN-\{beta\}Mediated IL-10 Production. J Immunol, 2010. 186(2): p. 675-84. 
83. Iyer, S.S., A.A. Ghaffari, and G. Cheng, Lipopolysaccharide-mediated IL-10 transcriptional regulation requires sequential induction of type I IFNs and IL-27 in macrophages. J Immunol, 2010. 185(11): p. 6599-607.

84. Kalliolias, G.D. and L.B. Ivashkiv, IL-27 activates human monocytes via STAT1 and suppresses IL-10 production but the inflammatory functions of IL-27 are abrogated by TLRs and p38. J Immunol, 2008. 180(9): p. 6325-33.

85. Strassmann, G., et al., Evidence for the involvement of interleukin 10 in the differential deactivation of murine peritoneal macrophages by prostaglandin E2. J Exp Med, 1994. 180(6): p. 2365-70.

86. Clark, K., et al., Phosphorylation of CRTC3 by the salt-inducible kinases controls the interconversion of classically activated and regulatory macrophages. Proc Natl Acad Sci U S A, 2012.109(42): p. 16986-91.

87. MacKenzie, K.F., et al., PGE(2) induces macrophage IL-10 production and a regulatorylike phenotype via a protein kinase A-SIK-CRTC3 pathway. J Immunol, 2013. 190(2): p. 565-77.

88. Murphy, K.M., et al., Signaling and transcription in T helper development. Annu Rev Immunol, 2000. 18: p. 451-94.

89. Szabo, S.J., et al., A novel transcription factor, T-bet, directs Th1 lineage commitment. Cell, 2000. 100(6): p. 655-69.

90. Zheng, W. and R.A. Flavell, The transcription factor GATA-3 is necessary and sufficient for Th2 cytokine gene expression in CD4 T cells. Cell, 1997. 89(4): p. 587-96.

91. Mowen, K.A. and L.H. Glimcher, Signaling pathways in Th2 development. Immunol Rev, 2004. 202: p. 203-22.

92. Veldhoen, M., et al., TGFbeta in the context of an inflammatory cytokine milieu supports de novo differentiation of IL-17-producing T cells. Immunity, 2006. 24(2): p. 179-89.

93. Ivanov, II, et al., The orphan nuclear receptor RORgammat directs the differentiation program of proinflammatory IL-17+ T helper cells. Cell, 2006. 126(6): p. 1121-33.

94. Saraiva, M., et al., Interleukin-10 production by Th1 cells requires interleukin-12-induced STAT4 transcription factor and ERK MAP kinase activation by high antigen dose. Immunity, 2009. 31(2): p. 209-19.

95. Chang, H.D., et al., Expression of IL-10 in Th memory lymphocytes is conditional on IL-12 or IL-4, unless the IL-10 gene is imprinted by GATA-3. European Journal of Immunology, 2007. 37(3): p. 807-17.

96. Shoemaker, J., M. Saraiva, and A. O'Garra, GATA-3 directly remodels the IL-10 locus independently of IL-4 in CD4+ T cells. Journal of Immunology, 2006. 176(6): p. 3470-9.

97. Zhu, J., et al., Conditional deletion of Gata3 shows its essential function in T(H)1-T(H)2 responses. Nat Immunol, 2004. 5(11): p. 1157-65.

98. Stumhofer, J.S., et al., Interleukins 27 and 6 induce STAT3-mediated $T$ cell production of interleukin 10. Nat Immunol, 2007. 8(12): p. 1363-71.

99. $\mathrm{Xu}, \mathrm{J}$., et al., c-Maf regulates IL-10 expression during Th17 polarization. Journal of Immunology, 2009. 182(10): p. 6226-36.

100. Corre, B., et al., Type I interferon potentiates T-cell receptor mediated induction of IL-10producing CD4(+) T cells. Eur J Immunol, 2013. 43(10): p. 2730-40.

101. Levings, M.K., et al., IFN-alpha and IL-10 induce the differentiation of human type $1 T$ regulatory cells. J Immunol, 2001. 166(9): p. 5530-9.

102. Vahedi, G., et al., Helper T-cell identity and evolution of differential transcriptomes and epigenomes. Immunol Rev, 2013. 252(1): p. 24-40.

103. Brownlie, R.J. and R. Zamoyska, T cell receptor signalling networks: branched, diversified and bounded. Nat Rev Immunol, 2013. 13(4): p. 257-69.

104. Dong, C., R.J. Davis, and R.A. Flavell, MAP kinases in the immune response. Annu Rev Immunol, 2002. 20: p. 55-72. 
105. Tussiwand, R., et al., Compensatory dendritic cell development mediated by BATF-IRF interactions. Nature, 2012. 490(7421): p. 502-7.

106. Murphy, T.L., R. Tussiwand, and K.M. Murphy, Specificity through cooperation: BATFIRF interactions control immune-regulatory networks. Nat Rev Immunol, 2013. 13(7): p. 499-509.

107. Macian, F., NFAT proteins: key regulators of T-cell development and function. Nat Rev Immunol, 2005. 5(6): p. 472-84.

108. Gerondakis, S., et al., Unravelling the complexities of the NF-kappaB signalling pathway using mouse knockout and transgenic models. Oncogene, 2006. 25(51): p. 6781-99.

109. Das, J., et al., A critical role for NF-kappa B in GATA3 expression and TH2 differentiation in allergic airway inflammation. Nat Immunol, 2001. 2(1): p. 45-50.

110. Chen, G., et al., The NF-kappaB transcription factor c-Rel is required for Th17 effector cell development in experimental autoimmune encephalomyelitis. J Immunol, 2011. 187(9): p. 4483-91.

111. Mori, N. and D. Prager, Activation of the interleukin-10 gene in the human Tymphoma line HuT 78: identification and characterization of NF-kappa B binding sites in the regulatory region of the interleukin-10 gene. Eur J Haematol, 1997. 59(3): p. 162-70.

112. Fitzgerald, D.C., et al., Suppression of autoimmune inflammation of the central nervous system by interleukin 10 secreted by interleukin 27-stimulated T cells. Nat Immunol, 2007. 8(12): p. 1372-9.

113. Batten, M., et al., Cutting edge: IL-27 is a potent inducer of IL-10 but not FoxP3 in murine T cells. Journal of Immunology, 2008. 180(5): p. 2752-6.

114. Spolski, R., et al., IL-21 mediates suppressive effects via its induction of IL-10. Journal of Immunology, 2009. 182(5): p. 2859-67.

115. Kitani, A., et al., Transforming growth factor (TGF)-beta1-producing regulatory T cells induce Smad-mediated interleukin 10 secretion that facilitates coordinated immunoregulatory activity and amelioration of TGF-beta1-mediated fibrosis. J Exp Med, 2003. 198(8): p. 1179-88.

116. Blokzijl, A., P. ten Dijke, and C.F. Ibanez, Physical and functional interaction between GATA-3 and Smad3 allows TGF-beta regulation of GATA target genes. Curr Biol, 2002. 12(1): p. 35-45.

117. Vahedi, G., et al., STATs shape the active enhancer landscape of $T$ cell populations. Cell, 2012. 151(5): p. 981-93.

118. Ciofani, M., et al., A validated regulatory network for Th17 cell specification. Cell, 2012. 151(2): p. 289-303.

119. Zhang, J.A., et al., Dynamic transformations of genome-wide epigenetic marking and transcriptional control establish T cell identity. Cell, 2012. 149(2): p. 467-82.

120. Fields, P.E., S.T. Kim, and R.A. Flavell, Cutting edge: changes in histone acetylation at the IL-4 and IFN-gamma loci accompany Th1/Th2 differentiation. J Immunol, 2002. 169(2): p. 647-50.

121. Lee, H.J., et al., GATA-3 induces T helper cell type 2 (Th2) cytokine expression and chromatin remodeling in committed Th1 cells. J Exp Med, 2000. 192(1): p. 105-15.

122. Ho, I.C., et al., The proto-oncogene c-maf is responsible for tissue-specific expression of interleukin-4. Cell, 1996. 85(7): p. 973-83.

123. Rengarajan, J., et al., Interferon regulatory factor 4 (IRF4) interacts with NFATc2 to modulate interleukin 4 gene expression. J Exp Med, 2002. 195(8): p. 1003-12.

124. Li, B., et al., Regulation of IL-4 expression by the transcription factor JunB during Thelper cell differentiation. EMBO J, 1999. 18(2): p. 420-32.

125. Kim, J.I., et al., The transcription factor c-Maf controls the production of interleukin-4 but not other Th2 cytokines. Immunity, 1999. 10(6): p. 745-51. 
126. Watford, W.T., et al., Tpl2 kinase regulates T cell interferon-gamma production and host resistance to Toxoplasma gondii. J Exp Med, 2008. 205(12): p. 2803-12.

127. Pot, C., et al., Cutting edge: IL-27 induces the transcription factor c-Maf, cytokine IL-21, and the costimulatory receptor ICOS that coordinately act together to promote differentiation of IL-10-producing Tr1 cells. Journal of Immunology, 2009. 183(2): p. 797-801.

128. Apetoh, L., et al., The aryl hydrocarbon receptor interacts with c-Maf to promote the differentiation of type 1 regulatory T cells induced by IL-27. Nature Immunology, 2010. 11(9): p. 854-61.

129. Pot, C., et al., Induction of regulatory Tr1 cells and inhibition of T(H)17 cells by IL-27. Seminars in Immunology, 2011. 23(6): p. 438-45.

130. Owaki, T., et al., IL-27 induces Th1 differentiation via p38 MAPK/T-bet-and intercellular adhesion molecule-1/LFA-1/ERK1/2-dependent pathways. Journal of Immunology, 2006. 177(11): p. 7579-87.

131. Fuqua, C.F., et al., Involvement of ERK-1/2 in IL-21-induced cytokine production in leukemia cells and human monocytes. Cytokine, 2008. 44(1): p. 101-7.

132. Rutz, S., et al., Transcription factor c-Maf mediates the TGF-beta-dependent suppression of IL-22 production in T(H)17 cells. Nature Immunology, 2011.

133. Motomura, Y., et al., The transcription factor E4BP4 regulates the production of IL-10 and IL-13 in CD4+ T cells. Nature Immunology, 2011. 12(5): p. 450-9.

134. Smith, A.M., et al., A distal enhancer in Il12b is the target of transcriptional repression by the STAT3 pathway and requires the basic leucine zipper (B-ZIP) protein NFIL3. J Biol Chem, 2011. 286(26): p. 23582-90.

135. Martins, G.A., et al., Transcriptional repressor Blimp-1 regulates $T$ cell homeostasis and function. Nat Immunol, 2006. 7(5): p. 457-65.

136. Iwasaki, Y., et al., Egr-2 transcription factor is required for Blimp-1 mediated IL-10 production in IL-27 stimulated CD4(+) T cells. Eur J Immunol, 2013.

137. Sun, J., et al., CD4+ T cell help and innate-derived IL-27 induce Blimp-1-dependent IL-10 production by antiviral CTLs. Nature Immunology, 2011. 12(4): p. 327-34.

138. Cretney, E., et al., The transcription factors Blimp-1 and IRF4 jointly control the differentiation and function of effector regulatory T cells. Nat Immunol, 2011. 12(4): p. 304-11.

139. Yu, D., et al., The transcriptional repressor Bcl-6 directs $T$ follicular helper cell lineage commitment. Immunity, 2009. 31(3): p. 457-68.

140. Johnston, R.J., et al., Bcl6 and Blimp-1 are reciprocal and antagonistic regulators of $T$ follicular helper cell differentiation. Science, 2009. 325(5943): p. 1006-10.

141. Nurieva, R.I., et al., Bcl6 mediates the development of T follicular helper cells. Science, 2009. 325(5943): p. 1001-5.

142. Liu, X., R.I. Nurieva, and C. Dong, Transcriptional regulation of follicular T-helper (Tfh) cells. Immunol Rev, 2013. 252(1): p. 139-45.

143. Kassiotis, G. and A. O'Garra, Establishing the follicular helper identity. Immunity, 2009. 31(3): p. 450-2.

144. Kusam, S., et al., Inhibition of Th2 differentiation and GATA-3 expression by BCL-6. J Immunol, 2003. 170(5): p. 2435-41.

145. Radtke, F., H.R. MacDonald, and F. Tacchini-Cottier, Regulation of innate and adaptive immunity by Notch. Nat Rev Immunol, 2013. 13(6): p. 427-37.

146. Rutz, S., et al., Notch regulates IL-10 production by Thelper 1 cells. Proc Natl Acad Sci U S A, 2008. 105(9): p. 3497-502.

147. Le Friec, G., et al., The CD46-Jagged1 interaction is critical for human TH1 immunity. Nat Immunol, 2012. 13(12): p. 1213-21. 
148. Kemper, C., et al., Activation of human CD4+ cells with CD3 and CD46 induces a Tregulatory cell 1 phenotype. Nature, 2003. 421(6921): p. 388-92.

149. Romano-Spica, V., et al., Role of ETS1 in IL-2 gene expression. J Immunol, 1995. 154(6): p. 2724-32.

150. Hollenhorst, P.C., RAS/ERK pathway transcriptional regulation through ETS/AP-1 binding sites. Small GTPases, 2012. 3(3): p. 154-8.

151. Lee, C.G., et al., Interaction of Ets-1 with HDAC1 represses IL-10 expression in Th1 cells. J Immunol, 2012. 188(5): p. 2244-53.

152. Grenningloh, R., B.Y. Kang, and I.C. Ho, Ets-1, a functional cofactor of T-bet, is essential for Th1 inflammatory responses. J Exp Med, 2005. 201(4): p. 615-26.

153. Chang, H.C., et al., PU.1 expression delineates heterogeneity in primary Th2 cells. Immunity, 2005. 22(6): p. 693-703.

154. Anderson, P., Post-transcriptional control of cytokine production. Nat Immunol, 2008. 9(4): p. 353-9.

155. Ivanov, P. and P. Anderson, Post-transcriptional regulatory networks in immunity. Immunol Rev, 2013. 253(1): p. 253-72.

156. Powell, M.J., et al., Posttranscriptional regulation of IL-10 gene expression through sequences in the 3'-untranslated region. J Immunol, 2000. 165(1): p. 292-6.

157. Nemeth, Z.H., et al., Adenosine augments IL-10 production by macrophages through an A2B receptor-mediated posttranscriptional mechanism. J Immunol, 2005. 175(12): p. 8260-70.

158. Stoecklin, G., et al., Genome-wide analysis identifies interleukin-10 mRNA as target of tristetraprolin. J Biol Chem, 2008. 283(17): p. 11689-99.

159. Carballo, E., W.S. Lai, and P.J. Blackshear, Feedback inhibition of macrophage tumor necrosis factor-alpha production by tristetraprolin. Science, 1998. 281(5379): p. 10015.

160. Neininger, A., et al., MK2 targets AU-rich elements and regulates biosynthesis of tumor necrosis factor and interleukin-6 independently at different post-transcriptional levels. J Biol Chem, 2002. 277(5): p. 3065-8.

161. Carballo, E., W.S. Lai, and P.J. Blackshear, Evidence that tristetraprolin is a physiological regulator of granulocyte-macrophage colony-stimulating factor messenger RNA deadenylation and stability. Blood, 2000. 95(6): p. 1891-9.

162. Franks, T.M. and J. Lykke-Andersen, TTP and BRF proteins nucleate processing body formation to silence mRNAs with AU-rich elements. Genes Dev, 2007. 21(6): p. 719-35.

163. Kedersha, N., et al., Stress granules and processing bodies are dynamically linked sites of mRNP remodeling. J Cell Biol, 2005. 169(6): p. 871-84.

164. Gaba, A., et al., Cutting edge: IL-10-mediated tristetraprolin induction is part of a feedback loop that controls macrophage STAT3 activation and cytokine production. J Immunol, 2012. 189(5): p. 2089-93.

165. Kratochvill, F., et al., Tristetraprolin-driven regulatory circuit controls quality and timing of mRNA decay in inflammation. Mol Syst Biol, 2011. 7: p. 560.

166. Bros, M., et al., The RNA binding protein tristetraprolin influences the activation state of murine dendritic cells. Mol Immunol, 2010. 47(5): p. 1161-70.

167. $\mathrm{Yu}, \mathrm{Q}$., et al., The role of the $\mathrm{p} 38$ mitogen-activated protein kinase, extracellular signalregulated kinase, and phosphoinositide-3-OH kinase signal transduction pathways in CD40 ligand-induced dendritic cell activation and expansion of virus-specific CD8+ T cell memory responses. J Immunol, 2004. 172(10): p. 6047-56.

168. Stoecklin, G., et al., MK2-induced tristetraprolin:14-3-3 complexes prevent stress granule association and ARE-mRNA decay. EMBO J, 2004. 23(6): p. 1313-24. 
169. Brook, M., et al., Posttranslational regulation of tristetraprolin subcellular localization and protein stability by p38 mitogen-activated protein kinase and extracellular signalregulated kinase pathways. Mol Cell Biol, 2006. 26(6): p. 2408-18.

170. Hitti, E., et al., Mitogen-activated protein kinase-activated protein kinase 2 regulates tumor necrosis factor mRNA stability and translation mainly by altering tristetraprolin expression, stability, and binding to adenine/uridine-rich element. Mol Cell Biol, 2006. 26(6): p. 2399-407.

171. Tudor, $\mathrm{C}$., et al., The p38 MAPK pathway inhibits tristetraprolin-directed decay of interleukin-10 and pro-inflammatory mediator mRNAs in murine macrophages. FEBS Lett, 2009. 583(12): p. 1933-8.

172. Sandler, H. and G. Stoecklin, Control of $m R N A$ decay by phosphorylation of tristetraprolin. Biochem Soc Trans, 2008. 36(Pt 3): p. 491-6.

173. Brewer, G., et al., Increased interleukin-10 mRNA stability in melanoma cells is associated with decreased levels of $A+U$-rich element binding factor AUF1. J Interferon Cytokine Res, 2003. 23(10): p. 553-64.

174. Chaudhry, A., et al., Interleukin-10 signaling in regulatory $T$ cells is required for suppression of Th17 cell-mediated inflammation. Immunity, 2011. 34(4): p. 566-78.

175. Yu, H., et al., MKP-1 regulates cytokine $m R N A$ stability through selectively modulation subcellular translocation of AUF1. Cytokine, 2011. 56(2): p. 245-55.

176. Brown, C.Y., et al., Differential regulation of the stability of cytokine mRNAs in lipopolysaccharide-activated blood monocytes in response to interleukin-10. J Biol Chem, 1996. 271(33): p. 20108-12.

177. Schaljo, B., et al., Tristetraprolin is required for full anti-inflammatory response of murine macrophages to IL-10. J Immunol, 2009. 183(2): p. 1197-206.

178. Pichon, X., et al., RNA binding protein/RNA element interactions and the control of translation. Curr Protein Pept Sci, 2012. 13(4): p. 294-304.

179. Forte, G.I., et al., Characterization of two alternative Interleukin(IL)-10 5'UTR mRNA sequences, induced by lipopolysaccharide (LPS) stimulation of peripheral blood mononuclear cells. Mol Immunol, 2009. 46(11-12): p. 2161-6.

180. O'Neill, L.A., F.J. Sheedy, and C.E. McCoy, MicroRNAs: the fine-tuners of Toll-like receptor signalling. Nat Rev Immunol, 2011. 11(3): p. 163-75.

181. Sharma, A., et al., Posttranscriptional regulation of interleukin-10 expression by hsa-miR106a. Proc Natl Acad Sci U S A, 2009. 106(14): p. 5761-6.

182. Ma, F., et al., MicroRNA-466l upregulates IL-10 expression in TLR-triggered macrophages by antagonizing RNA-binding protein tristetraprolin-mediated IL-10 mRNA degradation. Journal of Immunology, 2010. 184(11): p. 6053-9.

183. Sheedy, F.J., et al., Negative regulation of TLR4 via targeting of the proinflammatory tumor suppressor PDCD4 by the microRNA miR-21. Nature Immunology, 2010. 11(2): p. 141-7.

184. Dodeller, F., et al., The p38 mitogen-activated protein kinase regulates effector functions of primary human CD4 T cells. Eur J Immunol, 2005. 35(12): p. 3631-42. 